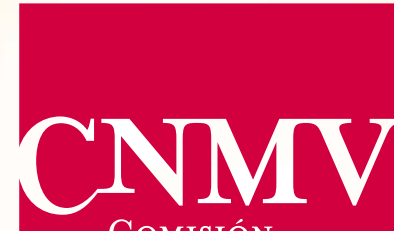

ComisióN

NAGIONAL

DEL MERGADO

DE VALORES
The credit default swap market:

Areas of vulnerability and regulatory responses

Óscar Arce

Javier González Pueyo

Lucio Sanjuán

Working papers

No 42 





\title{
The credit default swap market: Areas of vulnerability and regulatory responses
}

\author{
Óscar Arce \\ Javier González Pueyo \\ Lucio Sanjuán
}

\section{Working papers}

$\mathrm{N}^{\circ} 42$

October 2010

The authors would like to express their gratitude for the exchange of opinions and the comments and suggestions made by Rodrigo Buenaventura, Montserrat Martínez, Sergio Mayordomo, Antonio Mas and Fernando Restoy, and by the participants in the CNMV Department Seminar.

This Working Paper extends and updates the content of the article with the same title and authorship, published in the CNMV Bulletin corresponding to the second quarter of 2010 . 
The opinions in this Working Paper are the sole responsibility of the authors and they do not necessarily coincide with those of the CNMV.

By publishing this Working Paper Series the CNMV aims to disseminate research which contribute to the better knowledge of stock markets and their regulation.

The CNMV publishes most of its reports and publications via the Internet at www.cnmv.es

(C) CNMV. The contents of this publication may be reproduced, subject to attribution.

ISSN (printed edition): 2172-6337

ISSN (digital edition): 2172-7147

Legal deposit: BI-2910-2010

Layout: Composiciones Rali, S.A. 


\section{Abstract}

This document analyses the credit default swap (CDS) market, paying special attention to the main problems affecting the operation of this market and the various regulatory initiatives recently set in motion. With regard to the structure of this OTC (over the counter) market, the supply is highly concentrated in a few entities, which seems to condition both the level of transparency and the management of counterparty risk. In this context, we analyse the proposed regulatory amendments initiated in the USA and Europe which, on the one hand, help increase the transparency of transactions and will lead to a better supervision of the participating entities and more efficient price formation, and, on the other hand, help reduce counterparty risk by clearing standardised contracts in central counterparties (CCPs) and improve bilateral risk management for contracts which, due to their nature, cannot be cleared in CCPs. Lastly, we evaluate the advisability and effectiveness of restricting the naked buying of CDS. 



\section{Table of contents}

The essential features of CDS markets

2.1 Basic elements and recent trends in CDS and the structure of CDS markets

2.2 The relationship between CDS and interest rate spreads

3

CDS and systemic risk

4

Proposals for more transparent and safer CDS markets

4.1 Counterparty risk, transparency and standardisation: recent initiatives

4.2 Restrictions on naked CDS

5 



\section{Index of figures}

\begin{tabular}{llr} 
FIGURE 1 & Gross outstanding notional balance of CDS & 14 \\
\hline FIGURE 2 & Outstanding notional balance of OTC derivatives & 15 \\
\hline FIGURE 3 & Outstanding notional balance of bought and sold CDS by sector & 16 \\
\hline FIGURE 4 & Net (+/-) buyers/sellers of protection & 16 \\
\hline FIGURE 5 & Number and value of collateralised positions & 22 \\
\hline FIGURE 6 & CDS in iTraxx Europe and the spreads of their reference bonds & 23 \\
\hline FIGURE 7 & Government debt spreads over the German Bund and CDS over government bonds (bps) & 25 \\
\hline FIGURE 8 & Electronic confirmation of derivative trades & 37 \\
\hline FIGURE 9 & Confirmations sent in CDS trades by number of business days subsequent & 38 \\
\hline FIGURE 10 & Frequency of reconciliation of positions in the OTC derivative portfolios & 39 \\
\hline
\end{tabular}

\section{Index of tables}

TABLE 1 Net outstanding balance of sovereign CDS over volume of outstanding debt (\%) 



\section{Introduction}

The meteoric growth in the trading volume of credit default swaps (hereinafter, CDS) is one of the more visible aspects of the intense process of financial innovation that has taken place over the last twenty years. Particularly in the years preceding the outbreak of the global financial crisis in the summer of 2007, CDS, together with asset securitisation, emerged as instruments of massive credit risk transfer, and are now used in practically every segment of government and corporate debt markets.

While these instruments provide some undeniable advantages by theoretically enabling better risk allocation and management, with direct benefits for lenders and borrowers alike, CDS have been the target of various criticisms since the beginning of the current international financial crisis. The fact that some of the systemically important entities who have run into the greatest difficulties during the crisis, such as Lehman Brothers and the insurance company AIG, were leading players in the world CDS markets was a contributory factor for focusing the attention of analysts and regulators on these instruments. Later, the role of CDS as possible destabilising elements in the context of the recent European sovereign debt crisis has rekindled interest in these derivative products.

In this context, the purpose of this paper is twofold. Firstly, we provide an analysis of the various risk factors, of a general nature, present in CDS markets, with special reference to counterparty risk and the main drawbacks, mainly in terms of transparency, posed by the structure of bilateral and non-regulated trading which is typical in these markets. At the same time, we present some of the main regulatory initiatives formulated recently in Europe and the USA as well as other initiatives set in motion by the industry itself.

Secondly, our paper aims to throw light on the controversy aroused in connection with the possible destabilising role played by CDS in some European government debt markets in the context of the recent sovereign debt crisis. To this end, we present a critical review of some of the arguments which are frequently used to point out the possible harmful effects that CDS may have on sovereign debt markets and, consequently, on the funding conditions of affected States. Within the framework of the discussion, in the article we question the advisability of imposing, across the board, measures which impose excessive restrictions on the naked buying of sovereign CDS, in which the buyer of the derivative does not hold, at the time of buying, a direct interest in the underlying bond.

The rest of the article is structured in the following manner. Section 2 contains a description of the essential features of CDS contracts and of how these markets are structured, including the key figures which have characterised their development in recent years. Section 3 analyses the main risk elements present in CDS markets. Sec- 
tion 4 presents the most important measures which various authorities have recently proposed to strengthen and improve the functioning of these markets. This section also contains a critical discussion on restrictions to the naked buying of sovereign CDS. The final section presents the main conclusions of this paper. 


\section{The essential features of CDS markets}

\subsection{Basic elements and recent trends in CDS and the structure of CDS markets}

Credit default swaps or CDS are derivative instruments which allow the transfer of the default risk of a credit instrument between two counterparties. These products are mainly traded bilaterally on non-regulated, OTC markets. In the most common type of these contracts, the buying party, by paying a premium to the seller, obtains from that seller the obligation to pay the difference between the contractual value of the underlying credit or bond to which the CDS is referenced and its market value, if a credit event should occur. A credit event may take various forms of varying degrees of intensity, depending on the nature of the protected credit, including the bankruptcy of the issuer of the reference asset, the one-off default on payment obligations, and the restructuring of the debt. Thus, the buyer of a CDS hedges the credit risk of the reference asset although, at the same time, they take on a certain counterparty risk in respect of the seller of the contract, since if a credit event should occur, the effective protection provided by the CDS depends on the capacity or availability of the latter to meet their obligations.

With regard to what type of underlying credit asset can be protected by a CDS, the asset may be either government or corporate debt or may also be an index representing a basket of credits. This latter case is known as a 'multi-name CDS', due to the fact that the contract has an index of multiple references, as opposed to when the protection is linked to the debt of a single issuer, which is usually referred to as a 'single-name CDS'. Thus, generally speaking, the underlying asset may cover all the issuances made by a company or a sovereign State, or only a single specific issuance. Finally, there are also CDS which have structured products such as assetbacked securities as their underlying.

Figure 1 shows the recent trend in the gross outstanding notional balance of CDS worldwide for the various types of contracts mentioned above. ${ }^{1}$ These historical series illustrate some of the most significant aspects of the recent development of these products, such as their exponential growth during the years immediately following the outbreak of the crisis (in 2007, the outstanding balance represented as much as $105 \%$ of world GDP), the minor role played by sovereign CDS compared with contracts whose underlying assets are corporate debt (although the latter was

1 The outstanding notional balance of CDS is the sum of the nominal values of all unsettled contracts at the reporting date of entities filing declarations, adjusted to take into account transactions which would involve duplicate accounting (a transaction between two entities reported twice). This figure represents the maximum protection specified in the contract in the event of default. 
the only type to increase from June 2009 to June 2010 , in line with the greater relative importance of government debt over corporate debt issues) and the increase in the relative importance of multi-name CDS over the last five years. ${ }^{2}$

\section{Gross outstanding notional balance of $\mathrm{CDS}^{1}$}

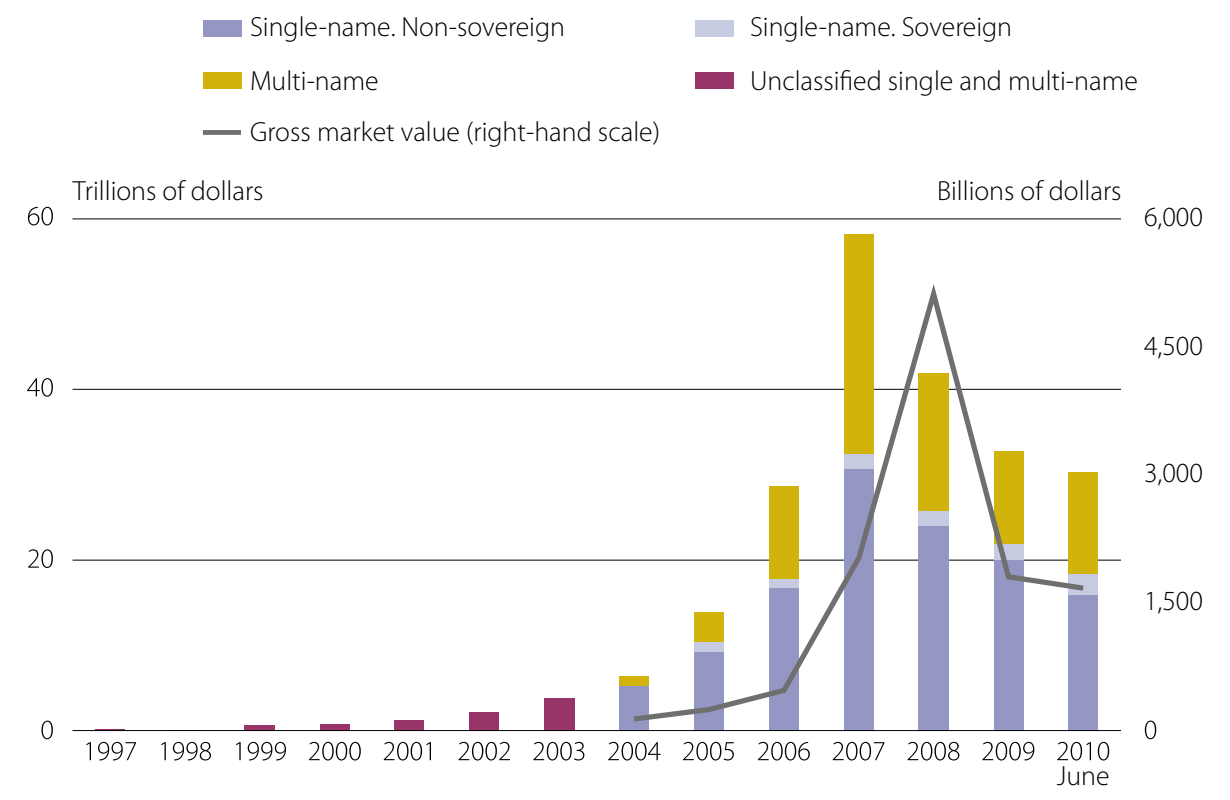

Source: IMF and BIS.

1 Figures for the period 1997-2003 are from the IMF, while figures corresponding to subsequent years are from the BIS. The breakdown between single and multi-name is available from 2004 on, while the breakdown between single-name sovereign and non-sovereign reference assets is only available as of 2005.

The fall in the outstanding volume of CDS which occurred at the beginning of the most acute phases of the crisis, mainly after September 2008 , is another of the more striking observations, although the main reason for the fall was not the general retrenchment of financial activity since then, but rather the introduction of operational improvements and new standardisation rules for the trading of these products, which have resulted in a marked compression of gross volumes due to the netting of opposite positions. ${ }^{3}$

Figure 1 also shows that the trend in the gross market value of the outstanding balance of CDS, which represents the price that the market assigns to the insurance provided by these derivatives, depends positively on the likelihood of a credit event and on the expected loss in that case. We may thus intuit that, at the midpoint of the

2 Most multi-name CDS are referenced to corporate debt indices, although they may also be referenced to certain sovereign indices. According to data from the US securities depository Depositary Trust \& Clearing Corporation (DTCC), at the end of May 2010 the outstanding notional balance of CDS referenced to sovereign indices, in gross terms scarcely accounted for $1.8 \%$ of all multi-name CDS. Meanwhile, over $92 \%$ of the gross outstanding notional balance of sovereign CDS recorded at the end of May in the DTCC were single-name CDS.

3 The compression of CDS contracts has enabled the gross outstanding notional balance to shrink to 25.3 billion dollars at the end of 2009, from estimates close to 62 billion dollars in 2008, according to DTCC data. 
most acute phase of the global financial crisis, towards the end of 2008, this variable would have reached its high point.

Meanwhile, Figure 2 shows the trend in the composition of OTC derivatives. As this figure shows, despite the rapid expansion of CDS in recent years, it should be stressed that these products still represent only a very small part of the total volume of OTC derivatives. In particular, the volume of notional balances of CDS in June 2010 accounted for just $5.4 \%$ of the total volume of derivatives traded on OTC markets, where interest rate swaps, which have existed for longer than CDS, account for the lion's share of trading.

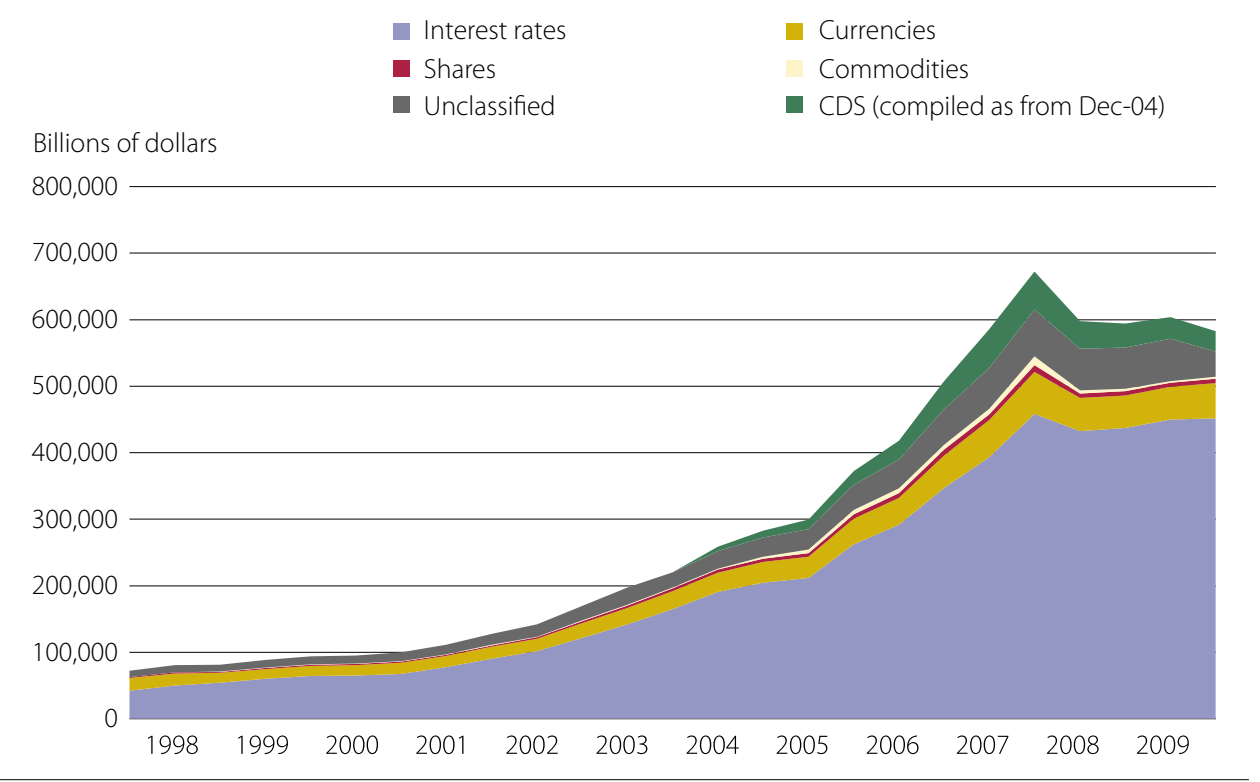

Source: BIS.

With regard to the type of participants in these markets, it should be noted that, by and large, on both the demand side and the supply side, the most active players tend to be major financial institutions. In particular, according to data published by the British Bankers Association (BBA, 2006) based on a panel of participants active in the trading of CDS worldwide, the demand for CDS in the period 2000-2006 mostly came from banks, although their market share in the purchase of protection shrank progressively during those years in favour of hedge funds (see the left-hand side panel of Figure 3). Other regional reports also show that banks are the main customers for these products. Thus, according to a survey conducted by the Banking Supervision Committee of the European System of Central Banks (see BCE, 2009), for $47 \%$ of European Union banks CDS were an 'important' tool for protecting against credit default risk, while for $23 \%$ these instruments were 'very important'. For the subset of larger European banks, in both cases the above percentages were higher still, reaching as much as $50 \%$. Meanwhile, according to data from the International Swaps and Derivatives Association (ISDA), 4 in $2009,88 \%$ of banks in the USA regularly used CDS. 


\section{Protection bought}

Banks and investment service companies

- Hedge funds

- Investment

- Other

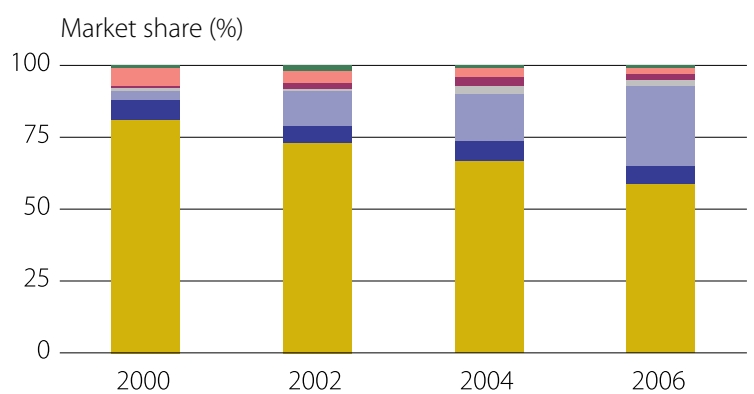

\section{Protection sold}

Insurance companies

Pension funds

Non-financial institutions

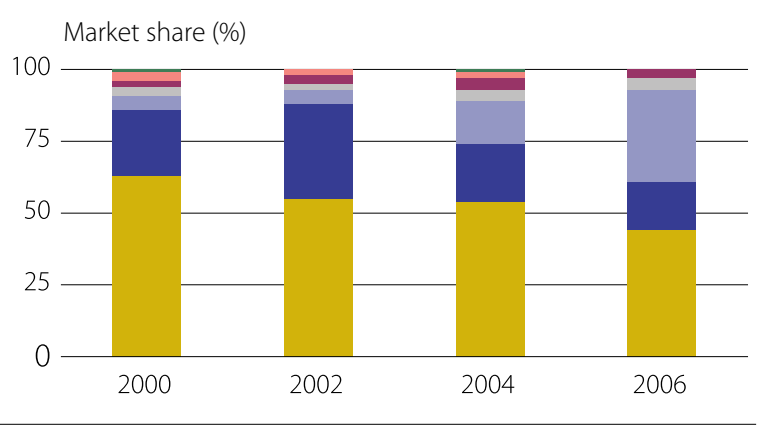

Source: BBA.

1 According to the data from a panel of 30 participants active in the trading of CDS, resident in various geographic areas. The outstanding notional balance of CDS estimated by the BBA in 2006 accounts for $71 \%$ of the figure published by the BIS for that year.

Net buyers/sellers (+/-) of protection

Banks and investment service companies

Hedge funds

- Investment funds

- Other

$50 \%$

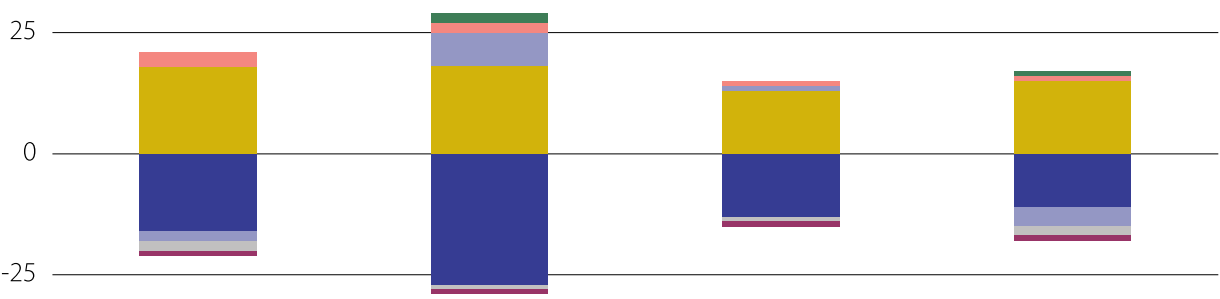

$-50$

2000

Source: BBA.

With regard to the most active sellers in CDS markets, in gross terms they tend to be major institutions operating on a global scale, mainly banks. According to the panel of participants surveyed by the BBA, the supply of CDS between 2000 and 2006 was concentrated, albeit to a lesser extent than on the demand side, in Banks. As occurred on the demand side, hedge funds accounted for a growing share (see the right-hand side panel of Figure 3).

In terms of net positions by sector, as shown in Figure 4, the banking sector has typically been a net buyer of protection, while insurance companies (including 
monolines) continue to be more important as net sellers. However, after the US government's bailout of AIG in 2008, the relative exposure of insurance companies must have fallen drastically since AIG was the most active participant in the CDS market in this sector. 5

The fact that the banking sector occupies a dominant position as both seller and buyer of CDS reflects the fact that this sector contains the most active dealers in these markets. Meanwhile, due to the high level of concentration in a relatively small number of large corporations, the structure of the dealing industry in these markets constitutes one of its most characteristic features, with significant implications on how they operate, as we will see later. Thus, according to data from the USA Treasury, ${ }^{6}$ at the end of 2008 five commercial banks (JP Morgan Chase, Bank of America, Citibank, Goldman Sachs and HSBC) accounted for practically all (99\%) of the buyers and sellers in that country. Meanwhile, according to data from the DTCC, in April 2009 the five largest sellers of CDS worldwide accounted for $49 \%$ of the total supply of these instruments, and the ten largest sellers accounted for $72 \%$ of the supply. ${ }^{7}$

A survey conducted by Fitch in $2009^{8}$ on a sample of 29 active participants in the CDS market from various countries points to a recent increase in the level of concentration in the sector: in that year the five participants with the greatest exposure accounted for $95 \%$ of the outstanding notional balances of bought and sold CDS, compared with $88 \%$ in 2008 . Moreover, the level of concentration in this market, taking into account the ten most mentioned participants in the survey, rose from $67 \%$ of the total exposure in 2008 to $78 \%$ in 2009 .

The fact that the entities offering CDS are normally large is to a certain extent a natural consequence of the positive relationship which tends to exist between size and the ability to raise funds, on the one hand, and solvency in terms of capacity as insurers against the default risk of large corporations and even sovereign States, on the other. However, some authors (see, for example, Litan, 2010) point out that the existence of implicit government guarantees for major financial institutions is a decisive factor in their capacity to supply this type of asset.

Thus the high level of concentration of the CDS market and the large average size of the sellers of these products, together with the risk profiles of the contracts themselves, differentiate these contracts from other OTC derivatives. These characteristics exert an influence on the management of counterparty risk but do not mean that improvements cannot be incorporated in response to a number of deficiencies that have come to light during the crisis.

5 In fact, in the survey conducted by Fitch Ratings (2009) on the global CDS market in 2008, the insurance industry was excluded due to its low exposure to these derivatives in comparison with the banking sector. In the 2009 survey (see Fitch Ratings, 2010), the sector was also excluded.

6 See http://www.occ.treas.gov/ftp/release/2009-34a.pdf.

7 This high degree of concentration increased on the back of the crisis as a result of the disappearance of participants who were very active in these markets, such as Lehman Brothers, Bear Stearns and the purchase of Merrill Lynch by the Bank of America.

8 See Fitch Ratings (2009 and 2010). 


\subsection{The relationship between CDS and interest rate spreads}

In theory, the spreads or differentials of bonds over risk-free assets and the premiums of the corresponding CDS should be closely related, since both are indicators of the default risk of the reference debt. In fact, in a frictionless economic environment, the two variables should coincide absolutely since otherwise there would be unexploited arbitrage opportunities. Empirical evidence regarding this point supports the existence of a close correlation between the two variables, especially when their behaviour is evaluated over a long period of time. ${ }^{9}$ However, the presence of some friction affecting the functioning of these markets may give rise to not inconsiderable differences between the price of CDS and the spread of the underlying bond. ${ }^{10}$ These differences which, in principle, may be either positive (if the spread is lower than the price of the CDS) or negative (in the opposite case) are normally referred to as 'bases'.

Among the factors which may drive the value of the bases most directly are: ${ }^{11}$

Factors tending to generate a positive basis:

- The existence of an implicit option of delivering the cheapest bond of the class of bonds hedged by the same CDS contract to the buyer in the event of a credit event occurring (cheapest-to-deliver option). This possibility enables the buyer of the CDS to obtain an additional benefit and, consequently, the value of the corresponding option is incorporated in the form of higher CDS premiums.

- Possible divergences between the clauses defining a credit event in a CDS contract and what, in effective terms, a default of the reference bond means for the holder of that bond. Under many CDS contracts, credit events much less severe than default, including several soft credit events, will trigger the seller's obligation to compensate. In exchange for a greater scope of coverage, the CDS premiums can consistently exceed the spread of the underlying bond.

- In scenarios of high demand for protection against default, protection by purchasing CDS may be a more accessible option for some investors than naked short selling the reference bond, which constitutes a transaction equivalent to the acquisition of a CDS on the spot market. Thus, the presence of friction in credit markets (for example, debt limits) may limit the accumulation of short positions in the bond and/or increase the cost of maintaining those positions, giving rise to a greater increase in the demand for CDS than would be seen if such friction was not present and, consequently, to an increase in the basis.

9 See, for example, Hull et al. (2002), Blanco et al. (2005), Zhu (2006) and Alexopoulou et al. (2009).

10 In a recent study using data for the period 2005-2009, Mayordomo, Peña, and Romo (2009) found that in the European corporate fixed income and CDS markets there were persistent deviations between the CDS premium and the spread of the corresponding bond.

11 For a more detailed analysis of the mechanisms by which these factors affect CDS and bond prices, see, Longstaff et al. (2005), De Wit (2006) and Attinasi et al. (2009). 
- $\quad$ Factors tending to generate a negative basis:

- The existence of counterparty risk, which is understood as the possibility that the seller does not meet the terms of the agreement in the event of a credit event, and tends to reduce CDS premiums. ${ }^{12}$

- In situations of strong demand for long positions in the underlying bond risk, the sale of CDS tends to be a more accessible option than the direct acquisition of the bond, as it does not require any initial disbursement. ${ }^{13}$ In this context, the presence of friction limiting or reducing the financing of long-term bond transactions may give rise to negative bases.

In addition, and generally speaking, there are a number of factors that may give rise to either a positive or negative basis, contribute to its persistence, or extend it. Listed below are some of these factors:

- The degree of relative liquidity in the various markets tends to tilt the value of the basis in one direction or another. For example, a higher level of liquidity in the bond market compared with the CDS market causes, ceteris paribus, an increase in the price of the bond, reducing its spread without this directly affecting the value of the CDS, at least not in principle. $^{14}$

- As was pointed out in section 3 of this article, the poor transparency of CDS markets, in which, generally speaking, there is no real-time public information on prices and transactions, makes it difficult to arbitrate positive or negative bases, which may add an element of persistence to those bases.

- The high level of concentration of CDS suppliers in a relatively small number of entities may also give rise to these products having premium spreads which do not reflect the risk incurred but rather are the result of a lack of competition between the selling parties. Up until now, however, there has hardly been any information or analysis on the size of these possible monopoly profits and their behaviour over time.

Arce, Mayordomo and Peña (2010) analyse the effect that some of the above mentioned factors may have on deviations between the bond spread and the CDS premium, using data corresponding to bonds and sovereign CDS in the context of the recent European government debt crisis. These authors find that funding costs, counterparty risk, the relative liquidity of CDS compared with bonds, the transpar-

12 However the impact of this factor should be significantly reduced once a major part of CDS contracts are settled in central clearing houses, as analysed previously.

13 In transactions in which the selling party has to provide guarantees (see later in this document), this difference is logically reduced.

14 Available data on the relative liquidity levels of different bonds, whether private or sovereign, does not however allow us to conclude with any degree of generality that either one of these two markets tends to be systematically more liquid than the other, but rather these differences vary depending on the particular bond and CDS in question. 
ency of the CDS market, and global risk (estimated by means of the VIX) have a significantly negative effect on the basis. In other words, an increase in any of these variables will tend, on average, to reduce the difference between the spreads of the CDS and its corresponding bond. On the other hand, the cheapest-to-deliver option and investor preference for sovereign bonds over any other type of asset have a significantly positive effect on the bases. ${ }^{15}$

15 Elizalde and Doctor (2009) provide evidence in favour of the influence of funding costs on the basis. Trapp (2009) finds that the base is closely linked to the specific risk of the underlying company, liquidity, and other market conditions. A detailed description of the base from various perspectives with regard to its development, trading and calculation can be found in Elizalde, Doctor and Saltuk (2009). 


\section{CDS and systemic risk}

Since the start of the crisis, CDS have often been highlighted as a generator of systemic risk. In order to shed some light on this issue, this section analyses some of the main aspects of CDS markets which might contribute to the high level of vulnerability of the financial system as a whole. Specifically, the analysis presented below refers firstly to several widely-agreed risk factors, such as the non-regulated nature of these markets and their lack of transparency and, secondly, the controversy generated around the role of CDS in the context of the recent turbulence in several European sovereign debt markets

The bilateral nature of CDS trading, in which trades are often carried out verbally, has facilitated the development of these products, which in many cases respond to very specific needs of the buying counterparty. However, this trading structure is partly to blame for the lack of transparency of these markets and the not inconsiderable level of counterparty risk.

With regard to this latter type of risk, it should be noted that CDS contracts normally involve some temporary but highly uneven obligation flows between the buying and the selling party. Thus, in the event of a credit event, the potential risk to which the buyer of the derivative is exposed in the event of the seller defaulting is substantially higher than the seller's risk throughout the entire life of the contract since, if the buyer fails to pay the premium, the seller of the CDS can simply opt out of the liability to which the contract binds him. As several authors have recently pointed out, ${ }^{16}$ this circumstance normally results in the counterparty risk associated with these products being much higher than that of other OTC derivatives, such as interest rate or exchange rate swaps, in which the obligation flow during the life of the contract is much more balanced between the two parties.

In practice there are several mechanisms which can mitigate the counterparty risk arising from credit derivative transactions, among which we should mention the opening of opposite positions to the existing ones, the provision of financial guarantees from third-party entities which will reimburse any losses incurred, and capital maintenance against the exposure by requiring collateral or guarantees which can executed in the event of default. ${ }^{17}$

With regard to this latter mechanism, Figure 5 shows how the use of guarantees or collateral in credit derivative contracts has increased considerably over the last ten

16 See, for example, Duffie and Zhu (2010) and Litan (2010). Arora et al. (2009) provides evidence regarding the level of counterparty risk through its impact on the spread of CDS issued by a broad spectrum of corporate issuers, which suggests that counterparty risk is a significant factor.

17 See ISDA (2010). 
years, in line with the trend for OTC derivatives as a whole. However, since the middle of the last decade there has been a certain stagnation in the growth of the degree of coverage, such that by the end of 2009, 34\% of all credit derivative exposures were not backed by any collateral (in terms of number of contracts, naked positions represented $29 \%$ of the total).

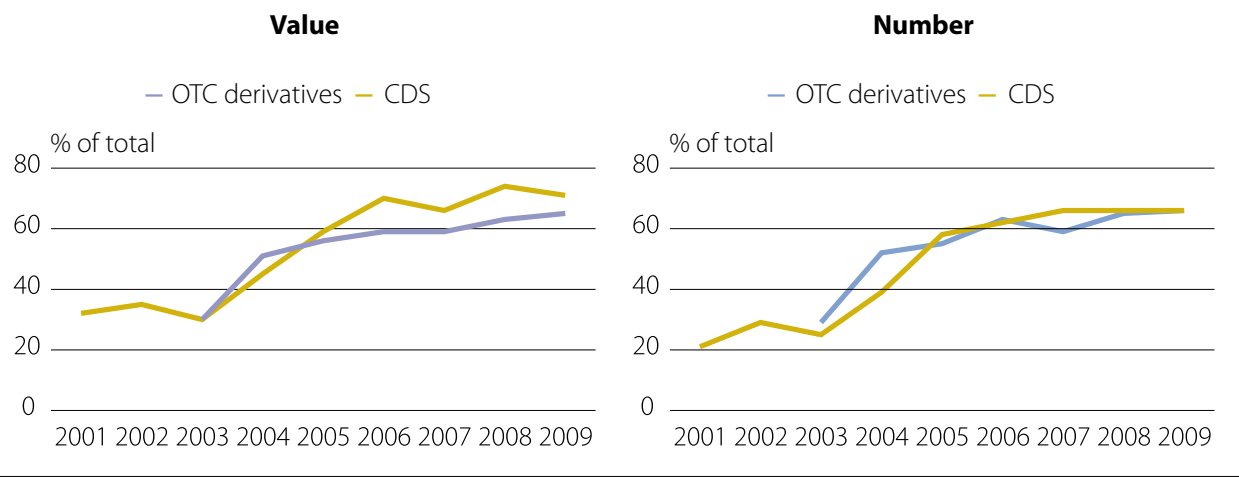

Source: ISDA.

In any event, recent experience suggests that the level of usage of guarantees in these contracts in recent years may have been insufficient to contain counterparty risk in situations of high financial instability. In particular, in a context of instability, it may be more difficult to increase guarantee requirements subsequent to the origination of the contract, which, in turn, may lead to greater level of aggregate risk, as happened in the case of the US insurance giant, AIG. At the end of the summer of 2008, this company had sold CDS to a net value of over 370 thousand million dollars, ${ }^{18}$ many of which had complex structured products as their underlying assets, such as collateralised debt obligations (CDO). A major percentage of the contracts sold by AIG were under-collateralised and, at the time, there was little information available, not only for AIG's various counterparties but also for the supervisory authorities. In that context, the rating agency Standard \& Poor's substantially reduced AIG's debt rating, which immediately prompted its counterparties to ask for more collateral. The inability of the insurance company to raise the necessary funds led to its near collapse.

Thus, one of the lessons we can learn from that episode is that the markedly cyclical behaviour of the value of both CDS contracts and the assets which normally serve as collateral for those contracts and the equity position of the entities selling CDS may cause sharp and significant variations in the perception of counterparty risk.

Another of the episodes in this crisis which has demonstrated the significant counterparty risk existing in these markets was the collapse of Lehman Brothers. In the years prior to its collapse, this investment bank was one of the most active CDS global counterparties. However, unlike AIG, Lehman basically acted as a dealer rather than a net provider of protection. In addition, the data available shows that the positions held by

18 See European Central Bank (2009). 
this bank were better collateralised than in the case of AIG. ${ }^{19}$ However, the fact that many counterparties offset opposing positions with Lehman by executing new contracts and not by cancelling pre-existing positions helped increase the number of such contracts linked to this investment bank over many years. The sudden collapse of Lehman triggered fears about a collapse of the CDS market worldwide.

In short, the episodes described above served to produce a broad consensus regarding the systemic risk that could be generated by a CDS market model based on bilateral trading which, on occasions, is very under-collateralised. Figure 6, which sets out the recent trend in the European corporate CDS index iTraxx, together with the average spread of the bonds making up that index, shows the appearance of a significantly negative basis coinciding with the worsening of the global crisis in September 2008. This observation, which tallies with the arguments put forward previously, may be a reflection of the sudden increase in the general perception of counterparty risk in CDS markets which occurred as a result of the problems that AIG and Lehman ran into.

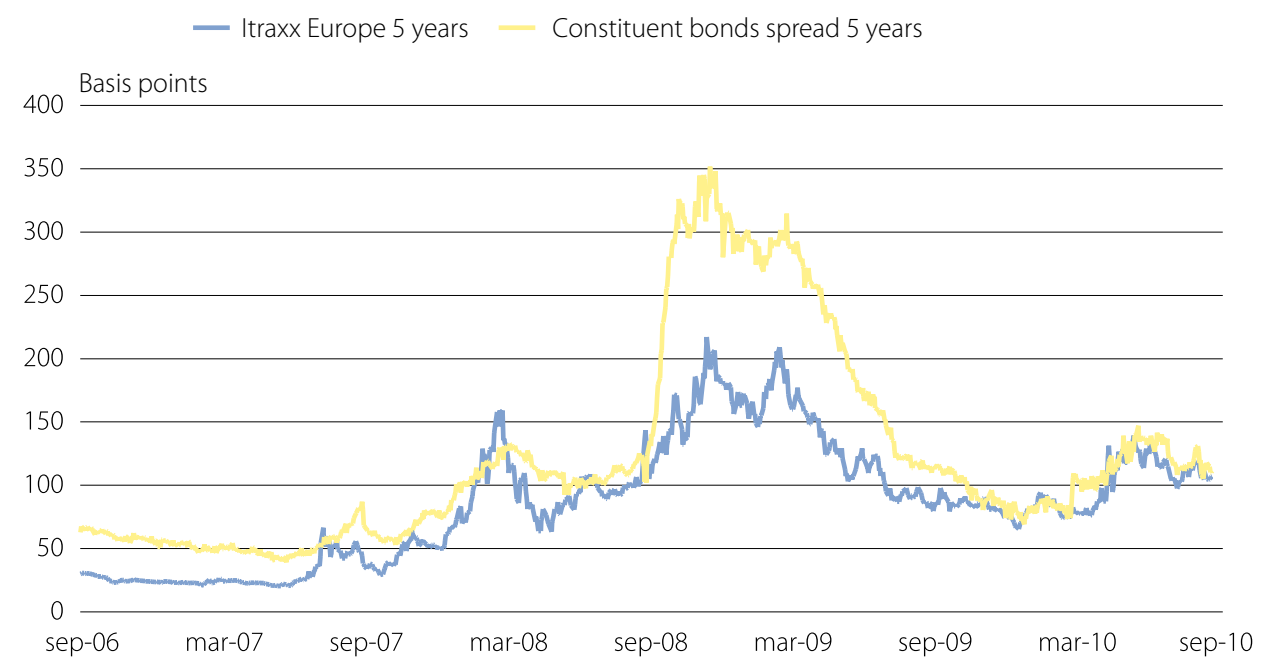

Source: Bloomberg. Data up to September 17.

1 The index iTraxx Europe refers to an equally weighted average of CDS referenced to the most liquid European corporate bonds. The spread of these bonds is calculated by subtracting their yields from the five-year IRS (interest rate swap) curve. This latter reference is a financial derivative whereby variable rate interest flows are swapped for fixed rate ones.

The very structure and nature of the sector of CDS sellers may have exacerbated other risks present in these markets. Thus, the disappearance of some of the most active investment banks in these markets, such as Lehman Brothers and Bear Sterns, brought about an automatic increase in the level of concentration of CDS sellers, with the consequent increase of the market risk illiquidity. Also, the concentration of growing volumes of positions in a shrinking number of entities may have caused substantial difficulties for the management of credit risk hedges. Since buyers of CDS tend to hedge part of the counterparty risk by acquiring a CDS from a third

19 See Stulz (2010). 
party entity, as the number of entities selling these contracts shrinks so risk spreading becomes more difficult while the possibility of circularity problems arising in the allocation of risks increases, with the consequent reduction in the capacity of the system as a whole to absorb negative distortions. ${ }^{20}$

One of the ways CDS can generate systemic risk lies in the possibility they provide of assuming/transferring the credit risk of any reference asset. The most obvious example of this is the sub-prime crisis in the USA. Without the use of synthetic securitised bonds structured as CDS contracts, the effects of the property crisis would probably to a large extent have been limited to the volume of mortgage loans granted in the USA. However, the issue of synthetic bonds allowed investors from all over the world to take a credit risk position in the US residential property market far greater than the outstanding balance of mortgages granted, with very adverse consequences for investors with no direct interest in that market.

In addition to the above mentioned risk factors we should also include the absence of any pre- or post-trade transparency regimes. In fact, buyers of CDS do not normally have access to information about buying or selling prices. Instead the price of each transaction is agreed directly with the issuer in question. In this respect several authors have suggested that the high level of concentration of sellers may be a barrier to the implementation of pre-transparency standards in this industry. ${ }^{21}$ Moreover, in spite of the fact that there are several private suppliers of data on trading prices and volumes, they rarely provide daily information on actual transactions but rather provide average values published with a certain time lag. There is also a high degree of disparity between the various sources of information available, which results in a very low level of post-transparency. Thus, Mayordomo, Peña and Schwartz (2010) compare six of the main sources of CDS prices using information relating to the most liquid references in the period 2004-2010, and they find systematic differences between the various sources. Furthermore, these authors argue that the disparity between the various sources is not random but is partly due to idiosyncratic factors. The same study also provides evidence suggesting that not all sources of data concerning CDS trades reflect the information with the same degree of accuracy. ${ }^{22}$

In addition to the above deficiencies - trading based on non-regulated bilateral relationships with limited transparency - another possible generator of systemic risk in CDS markets has appeared on the scene, which is related to the hypothetical role of CDS as a destabiliser of sovereign debt markets. Thus, as a result of the recent tightening of funding conditions for a number of European countries, several analysts and even some political and economic authorities have pointed to the possible existence of speculative and even manipulative practices in sovereign CDS markets, whose effects on the government debt markets would, according to this hypothesis, have manifested themselves in higher risk premiums and generally less favourable funding conditions for those States with a more vulnerable fiscal condition.

20 BCE (2009) contains a detailed analysis of how the problem of risk circularity may arise and presents some evidence in this respect.

21 This matter is analysed in detail by Litan (2010) in the more general context of the incentives that might cause the major CDS sellers to oppose an in-depth reform of these markets.

22 Specifically, these authors find that the information from one of the sources analysed behaves like an advance indicator of credit risk in respect of the other sources. 


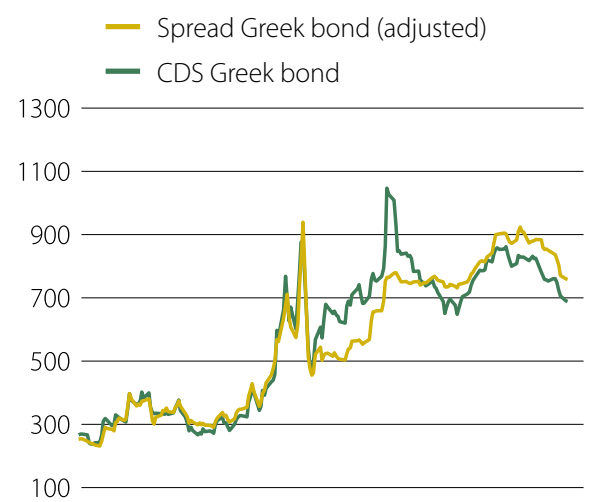

ene-10 mar-10 may-10 jul-10 sep-10

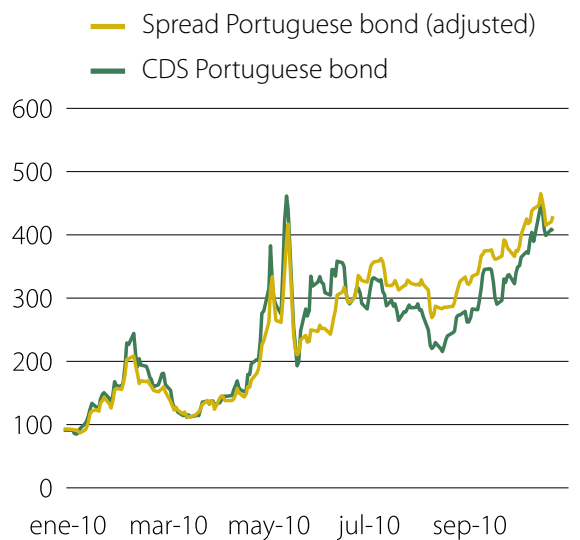

- Spread Irish bond (adjusted)

- CDS Irish bond

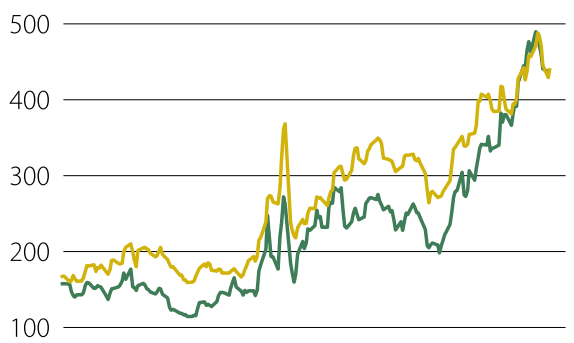

0

ene-10 mar-10 may-10 jul-10 sep-10
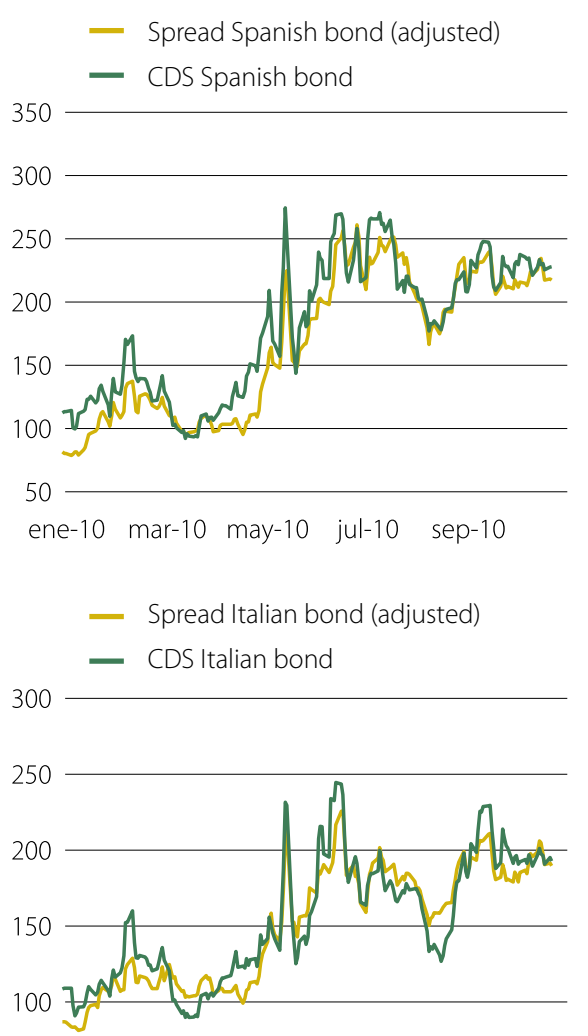

50

ene-10 mar-10 may-10 jul-10 sep-10

- Spread French bond (adjusted)

- CDS French bond

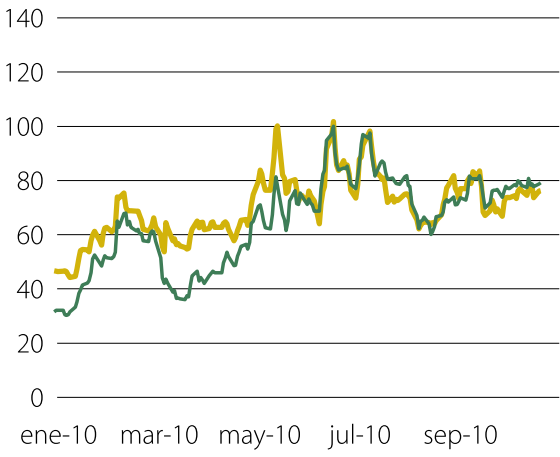

Source: Thomson Reuters Datastream. Data up to October 5.

1 To calculate the spread the CDS premium of the German government bond has been added to the spread of that bond in order to approximate the price of a risk-free asset, using the following formula: spread of the bond of country $A=$ (Interest of the bond of country A - Interest of the German bond) + CDS Germany.

One of the observations which has sometimes served to provide empirical support for the above argument concerning the destabilising role of CDS is the fact that, coinciding with the rise in CDS prices and in spreads compared with German debt - which is typically considered to be the safest asset in the Eurozone - the difference between the two risk indicators has widened in recent months in a number of European countries, giving rise to a positive basis (see Figure 7). 
However, the strength of the above argument concerning the destabilising role of CDS lies in a number of elements, the validity of which is not assured, as we will see below.

Firstly, as was pointed out in section 2, there are objective reasons justifying the existence of temporary deviations between CDS and spreads and the apparent excess of volatility in sovereign CDS markets, among which are the following:

- In a macro-economic climate such as the one which has prevailed since the start of tensions in the European debt markets, characterised by a sharp deterioration in the perception of fiscal strength in some economies, the demand for hedging against default by means of CDS will normally tend to increase considerably, while demand which, as has been stressed previously, is concentrated in a small number of entities, may display a certain rigidity in the short term, which tends to augment the positive effect on CDS premiums and lead to an apparent excess of volatility.

- However, it is necessary to recognise that leadership of the CDS market in price discovery in response to variations in the perceived risk in the bond market is not assured on the basis of empirical evidence. Thus, despite the fact that the first studies to address this issue reached this conclusion using figures for corporate debt, ${ }^{23}$ other more recent studies have found that the bond market in question is sometimes more efficient when it comes to incorporating new information in prices. Thus, Mayordomo, Peña and Romo (2010) use data from a sample of European companies and find that, while the CDS market led bond markets and asset swap packages (ASP) prior to August 2007, this leadership changes subsequent to that date in favour of the latter two markets, largely due to changes in the relative level of liquidity between the various markets. With regard to European sovereign debt markets, Arce, Mayordomo and Peña (2010) provide evidence that in some jurisdictions and at some moments during the recent government debt crisis, bonds have reflected credit risk information more efficiently than CDS. Ammer and Cai (2007) make the same analysis applied to the sovereign debt of emerging markets and find that the bond spread leads the CDS price more often than we think. However, it must be recognised that the leadership of one market over another in the price discovery process does not necessarily mean that there are causal relationships in the setting of prices in the two markets. This latter observation makes it more difficult to argue, for example, that some distortion in the functioning of the CDS market will necessarily be reflected in price variations in the underlying bond.

Secondly, it should be stressed that any friction, rigidity or anomaly in the CDS market will not necessarily transfer in any significant manner to the market of the underlying bond, nor will it affect its prices in any significant way, for the following reasons:

23 See, for example, Norden and Weber (2004), Blanco et al. (2005), Zhu (2006), and Alexopoulou et al. (2009). 
- $\quad$ A higher CDS price than one compatible with the real risk of the bond will only transfer to the debt market if the market participants are willing to validate prices by their assets which are below their intrinsic or fundamental value. However, it is very difficult to imagine that this could occur in a systematic and persistent manner, since it would be tantamount to assuming that, in a bond market dominated by professional brokers, there would be sure win opportunities (arbitrage) unexploited over a long period of time.

- $\quad$ Neither does it appear to be feasible for there to be trades on the CDS markets aimed at intentionally affecting the prices of underlying bonds, since the bond market is normally much larger than the CDS market, as is shown by the data on the relative size of the two markets for various European countries set out in Table 1. What is more, these figures show that for some of the countries whose sovereign debt markets have suffered the greatest volatility throughout the year, the size of the CDS market in comparison with that of the underlying bond market has shrunk or has remained the same. Specifically, between March 2009 and May 2010, when the turbulence in both markets was at its height, this ratio shrank (as in Ireland) or remained practically unchanged (as in Greece or Spain). ${ }^{24}$

\section{Net outstanding balance of sovereign CDS over volume of outstanding debt (\%)}

TABLE 1

\begin{tabular}{lrrrr} 
& Nov $\mathbf{0 8}$ & Mar 09 & May 10 & Sep 10 \\
\hline Eurozone & 1.1 & 1.1 & 1.3 & 1.4 \\
\hline Germany & 0.7 & 0.6 & 0.8 & 1.0 \\
\hline Spain & 2.8 & 2.0 & 2.1 & 2.1 \\
\hline France & 0.4 & 0.4 & 0.7 & 0.7 \\
\hline Greece & 2.4 & 2.1 & 2.0 & 1.9 \\
\hline Ireland & 8.6 & 6.2 & 4.2 & 3.4 \\
\hline Portugal & 4 & 4.1 & 5.7 & 4.6 \\
\hline Italy & 1 & 1 & 1.2 & 1.3 \\
\hline
\end{tabular}

Source: DTCC, Reuters and CNMV

In short, while the existence of major risk elements in the functioning of CDS markets, linked to their bilateral nature and their lack of transparency, is unquestionable, at the same time we need to recognise that their role as a causal or exacerbating factor of the recent turbulences in several European government debt markets is based on considerably weaker evidence. ${ }^{25}$ In any event, any increase in

24 In terms of relative trading volume rather than outstanding balances the conclusion is similar, at least in the case of Spain. Thus, the daily average between June 2009 and June 2010 of the ratio between the trading volume of CDS and that of Spanish government debt was 13\%, according to DTCC figures (average trading volumes of CDS) and Spanish Treasury figures (simple transactions of Spanish government bonds).

25 For example, in a recent piece of research (the results were published in March 2010), the German BaFin concluded that there was no basis for supposing that the high volatility of prices of Greek sovereign debt could be attributed to the presence of significant speculative elements in the market of CDS referenced 
the transparency and safety of CDS trading will facilitate a better analysis of other possible problem factors, such as the presence of destabilising speculative activities or conduct aimed at manipulating the market, as is argued in the following section. 


\section{Proposals for safer and more transparent CDS markets}

In the context of the analysis presented in the previous point, this section analyses several recent proposals aimed at countering the main deficiencies in the functioning of CDS markets. Specifically, point 4.1 presents the main initiatives put forward for reducing counterparty risk, increasing transparency and raising the level of standardisation in contracts. Point 4.2 assesses the advisability of restricting naked purchases of CDS, those in which the buyer of the derivative does not simultaneously hold a position in the reference asset

\subsection{Counterparty risk, transparency and standardisation: recent initiatives}

\section{Reduction of counterparty risk}

The actions which in principle have the greatest potential to improve the management of counterparty risk are the establishment of incentives for clearing CDS in central counterparties (hereinafter, CCPs) and strengthening the bilateral management of collaterals for those contracts less fitted for clearing in a CCP.

There is a general consensus on those contracts which are, in principle, better suited to being settled in CCPs, which would include those with the highest degree of standardisation. On the other hand, other contracts developed to meet very specific needs would remain outside the CCP system due to their limited liquidity and greater complexity, since both factors complicate risk management. Thus, if a member of the CCP fails to meet its obligations, the CCP takes over the position of the defaulter and, from that moment on, is exposed to market risk. Faced with this contingency, the clearing house could choose to transfer the position to the rest of the clearing members or keep it and manage its orderly closing. In this latter case, if the contracts have a minimum of liquidity it would be more feasible to opt for the orderly and efficient closing of the position in the market, thereby limiting any possible additional losses. Otherwise, the clearing house would hold the contracts for longer and therefore the market risk assumed by the CCP would be greater.

However, a high level of specificity limits the potential for achieving economies of scale in settlement, which is one of the main benefits of a CCP. Also, one of the most important requirements for a contract to be settled in a CCP is that its risk profiles are easily recognisable so as to enable the margin requirements to be frequently and easily calculated. ${ }^{26}$

26 Contrary to the approach set out here, Hull (2010) proposes that all OTC contracts be settled in central clearing houses in order to maximise the benefits derived from reduced counterparty risk and increased 
In addition to the reduction in counterparty risk, the settlement of a significant percentage of OTC contracts in CCPs may help mitigate the problems of lack of transparency which OTC markets suffer from. This would not only benefit most of the participants in these markets, but it would also facilitate access to prudential information of great importance to market supervisors.

As has recently been highlighted by Duffie and Zhu (2010), among others, the clearing of CDS in a central counterparty with a suitable risk control system, appropriate capital levels, and strict supervision could substantially mitigate counterparty risk in these markets. However, the design and implementation of clearing in a CCP involves significant conceptual and practical difficulties. Some of the most complex aspects, about which there is little analysis, are those related to the optimum number of CCPs and the type of contracts that should be cleared in them, as we explain below.

One of the strategic decisions which needs to be taken in a coordinated manner between the supervisors involved is the decision as to the number of CCPs to be authorised to clear CDS. This decision involves a complex trade-off in which, on the one hand, the possibility of achieving economies of scale and network externalities intrinsic to a central counterparty requires a relatively small number of CCPs. However, the smaller the number of competing clearing houses, the greater the risk of monopolistic activity and concentration of high risk levels in individual entities. On this subject, Duffie and Zhu (2010) recognise the systemic importance which a central counterparty dealing with all CDS clearing could have, with all the problems in terms of aggregate risk in the event of a collapse and, consequently, of moral risk in the conduct of the managers of an entity of this nature. Given the systemic importance that CCPs might have in a scenario in which only a very few such entities existed, Cecchetti et al. (2009) suggest that it might be advisable for these entities to have access to the liquidity facilities of a central bank and other instruments of governmental support in order to anticipate and resolve possible simultaneous largescale defaults.

Another aspect to be considered is the exclusivity of the activity of a CCP and, in particular, the advisability of restricting its operations to CDS contracts and not admitting the clearing of other derivative contracts. On this issue, Duffie and Zhu (2010) advise against creating single purpose CCPs specifically for CDS. According to these authors, the current CDS market lacks the volume to offset the losses involved in not allowing the multilateral netting of different types of contracts, both in terms of potential risk mitigation for the CCP in question, and in terms of cost savings as a result of the lesser need to maintain guarantees which they would otherwise require if the CCP was not allowed to perform the simultaneous clearing of assets other than CDS.

As has already been mentioned, it should be borne in mind that, due to the particularities of the risk profile of CDS contracts, with their binary pay-off, which tend to give rise to greater price volatility than other derivatives, the guarantees demanded

transparency. However, the author does not explicitly consider the problems that might arise as a result of settling the very specific contracts referred to in this document in CCPs. 
from the sellers of CDS tend to be of a marked pro-cyclical nature. The clearing of CDS in CCPs could partially mitigate this behaviour, but it would not seem to be very feasible to expect it to eliminate it totally as credit risk itself has a high pro-cyclical component.

Another aspect to consider is that a CCP may exacerbate the problem of the circularity of CDS market risk mentioned earlier. In this respect, the role played by the risk management regime within the CCP and, in particular, the clearing fund, is especially important. The clearing fund is fed by the contributions of the members of the CCP and is used to resolve any default of a participant in the clearing house. Therefore, insofar as the current structure of the CDS market, with trading concentrated in a relatively small number of major entities with similar characteristics and business lines, will be transferred to the participatory structure of a CCP, significant risks may arise as a result of the close correlation between the positions of the participants in the CCP. This latter possibility suggests that, in order to increase the effectiveness of a CCP in terms of reducing idiosyncratic risk (with regard to the possibility of an individual participant defaulting on their obligations) it would be advisable to open up participation to a wider number of members and, possibly, to other derivatives other than CDS, in line with the argument forwarded by Duffie and Zhu (2010) mentioned earlier.

Finally, one risk which will not be automatically eliminated with the establishment of CCPs is in connection with the enormous influence that the major dealers exert over the CDS market, for whom a decrease in the volume of bilateral transactions and an increase in the level of transparency and supervision could lead to a reduction in their profits. ${ }^{27}$

With regard to regulatory matters, several authorities have already taken the first steps to promote the use of CCPs. One example is the G-2O which, in its September 2009 summit, proposed that all OTC contracts of standardised derivatives should be traded on organised markets or multilateral trading facilities (MTFs) and cleared in CCPs on a compulsory basis. For contracts with a lesser degree of standardisation, the G-2o proposed the establishment of greater capital requirements for participant entities, in order that they properly internalise the aggregate risk of OTC bilateral trading. The communiqué from the latest summit of G-20 leaders held to date (Toronto, June $26-27,2010$ ) reiterated this same proposal and set year-end 2012 as the deadline for all standardised OTC derivatives to be traded on organised markets or MTFs. Also, in this latest communiqué, the G-2o were in favour of introducing measures relating to the margins and guarantees applied to derivative contracts to enhance the stability of these markets and mitigate their pro-cyclical nature. ${ }^{28} \mathrm{Re}$ cently, in October 2010, the Financial Stability Board (FSB) published a document (see FSB, 2010) in which they set out in detail the general guidelines established by the G-2O in this respect and propose 21 specific recommendations for the reform of

27 Litan (2010) addresses this issue in great depth and identifies some possible elements of resistance to change on the part of major CDS dealers.

28 The regulatory initiatives set in motion in the USA and in the EU are a direct reflection of the general principles agreed on by G-20. Consequently, most of the new rules enjoy a high degree of consensus and coordination and will be implemented in the major financial markets of the world in a harmonised manner, thereby reducing the possibility of regulatory arbitrage. 
the OTC derivatives market. This same document contains some estimates regarding the volume of OTC contracts which are being cleared in CCPs, on the basis of data published by the DTCC and Trioptima. To be precise, according to these sources $31 \%$ of all interest rate swap contracts are already cleared in CCPs, a percentage which in the case of CDS drops to $13 \%$. The percentage of other OTC derivatives (with shares, commodities, and currencies as their underlying) cleared in CCPs is far below the two above mentioned categories.

Meanwhile, in October 2009 the European Commission (EC) announced its first proposals for regulatory change in this area, in order to implement the changes in the course of 2010 (see European Commission, 2009). In September 2010, the EC published its final proposal for the regulation of the CDS markets (see European Commission, 2010c), which will be submitted to the European Council and Parliament. Its main proposals in this area are centred on reducing counterparty risk and increasing transparency. More specifically, the EC proposes to oblige financial counterparties to clear all their OTC derivatives which meet a series of requirements, to be determined prior to 30 June 2012 by the future European Securities Market Authority (ESMA), in consultation with the European Systemic Risk Board (ESRB), in CCPs. As an exception to this general principle, non-financial counterparties of OTC derivatives will be exempt from this obligation, provided that their positions are hedges of trade risks or whenever a threshold to be set by the ESMA before June 2012 is not exceeded.

One of the most significant and novel aspects of the EC proposal is the incorporation of requirements affecting the CCPs, which follow the recommendations set out in the CPSS-IOSCO (2010) document. These requirements can be grouped in the following categories:

- $\quad$ Organisational requirements. New requirements are included in the area of corporate governance, with clearly defined lines of responsibility, including certain requirements for managers in matters of experience and reputation, and the creation of a risk committee composed of representatives of the clearing members and independent members of the Board, whose function will be to advise in the design of the risk management model of CCP's. The EC proposal also contains instructions regarding the procedures to be followed in the case of default and the criteria to be applied for the authorisation of new members and instruments.

- Transparency requirements. The CCPs are required to maintain records of all their transactions for ten years. The information stored must enable the original terms of the transactions to be identified and it will be necessary for them to have a business continuity and contingency plan. The proposal also establishes some thresholds for the disclosure of significant holdings in the capital of CCPs, which must be disclosed to the supervisory authority.

- $\quad$ Solvency. The proposal calls for a minimum initial capital of five million euros and the mandatory constitution of a default fund, which will be covered by the settling members in proportion to the positions and risks they have registered in the CCP. The amount of the fund must be enough to solve the hypothetical default of the settling member with the largest risk position or, if the total is 
greater, of the members with the second and third largest risk positions jointly. Furthermore, a different fund must be set up for each different class of instrument settled in the CCP, although it has not yet been specified exactly what is understood by "class of instrument". Such clearing funds already exist in several of the main CCPs currently operating, such as Eurex, LCH.Clearnet Ltd and CME Group. The fund effectively mutualises losses, as all the settling members assume any losses caused by the default of one of them up to the amount of their contribution to the fund, and incorporates incentives for the settling members themselves to increase their standards of rigour. The CCP must also demand margins that cover $99 \%$ of the price variations of the positions over an appropriate period of time and will limit the volume of open positions that the settling members can have to avoid the concentration of risk in a small number of entities. The national supervisors of the CCP will validate the parameters and models used for calculating the margins, for which they will have access to the opinion of the ESMA and of the markets on which the products settled in the clearing house are traded. The EC also stresses the need for the CCP to have access to adequate sources of liquidity, including facilities from the central banks.

With regard to supervision, in Europe it will be the ESMA which, at the request of a CCP, will declare whether the contracts are eligible for settlement in a clearing house. The ESMA will base its decision on the following criteria: reduction of systemic risk in the financial system, liquidity of the contracts, availability of prices, capacity of the CCP to manage a major volume of contracts, and level of protection that the clearing house provides to the participants.

In the case of contracts whose characteristics make them unsuitable for clearing in CCPs, bilateral risk management may also be improved and made more robust. To do this requires acting on two fronts. One of these is the already mentioned need to increase the use of margins and make daily mark to market of the contracts, as set out in the EC proposal, which also calls for the increased use of electronic trade confirmation whenever possible. These provisions will be applicable to both financial and non-financial counterparties. The ongoing review of the Capital Requirements Directive will differentiate capital consumption between positions in derivatives settled in a CCP and those which continue to be settled bilaterally outside the clearing houses. The second course of action is to increase legal robustness by setting up netting agreements which will allow the number of settlements to be reduced in the event of default by one of the participating counterparties.

An internal difficulty facing European regulators, as the EC itself recognises in its proposal, is the lack of harmonisation of the requirements and standards applicable to CCPs. This regulatory disparity means that the provision of services between different countries may be potentially more costly and less safe and may act as a barrier to the integration of the European financial markets. Thus, the existence of a great many CCPs in various jurisdictions means that any default will be treated in different ways, which will have negative consequences for participants in international transactions. In this respect, given the possible coexistence of several different legal regimes applicable to credit event situations, it would be advisable to move towards a more homogeneous pan-European legal treatment of defaults. 
In the United States, the Dodd-Frank Wall Street Reform and Consumer Protection Act, passed in July 2010, contains specific measures incorporating the recommendations of the G-20, including, as its most innovative aspect, the need for specific prudential supervision of the dealers and companies present in the CDS markets whose activity results in significant risk positions for their counterparties. In particular, the US legislator has entrusted the SEC and the Commodity Futures Trading Commission (CFTC) with the task of implementing some of the aspects of the DoddFrank Act, for the purpose of which a public consultation period has been set up during which time proposals for the regulatory treatment of the various aspects covered by the act can be submitted.

The Dodd-Frank Act creates two new categories of entities which must be registered to act in the CDS market: swap dealers and major swap participants. Both types of entities are obliged to settle all CDS that the CFTC considers to be standardised in CCPs, and CDS must be traded on regulated swap markets or trading platforms. This is one of the differences with the EC proposal, which does not include mandatory trading standardised CDS on regulated markets or multilateral trading facilities (MTFs). The CFTC will use a series of criteria to assess whether OTC derivatives must be settled in CCPs. Among these criteria are the level of liquidity of the CDS, the availability of information on prices, the outstanding contracts, and their effect in terms of systemic risk reduction, aspects which were also considered in the EC proposal.

When the CFTC considers CDS to be non-standardised, the dealers in the swap markets and the main participants will be subject to capital requirements for the positions they hold in portfolio. In these markets, the players will be obliged to maintain and update their margins in a similar manner to what is established in CCP risk control procedures.

One of the latest provisions to be included in the US reform is the $20 \%$ limit on participation in the capital of the CCP applicable to banks and dealers in the swaps market. This limit aims to mitigate the problem of the concentration of risk in a small number of members of the CCP, which, as mentioned earlier, currently characterises OTC activity, and the trading of CDS contracts in particular.

Given the structure of the CDS market, with a very significant presence of US banks which frequently carry out proprietary trading, the bill known as the "Volcker rule" may have been one of the decisive factors in the development of the CDS market. In principle, the initial wording of the rule included a ban on proprietary trading affecting all banks holding customer deposits and access to the Federal Reserve Discount Window, which might have significantly limited the activity of liquidity generators. In the end, in its final version, the restrictions were partially relaxed and the limitation was reduced to a limit to the assumption of risk of $3 \%$ of the tier 1 capital, which, a priori, should not affect most institutions.

Finally, the Dodd-Frank Act calls for the withdrawal of access to Federal Reserve facilities and even the insurance of the Federal Deposit Insurance Corporation (FDIC) to any credit institution which does not segregate its trading operations involving CDS not cleared in CCPs and CDS referenced asset-backed securities in a separate, adequately capitalised entity. For this reason, in spite of the fact that the new regulations came into force four years ago, some entities have already an- 
nounced their intention to cease proprietary trading activities in some areas such as derivatives on commodities. ${ }^{29}$

\section{Increase in transparency}

Transparency may refer to the level of information available on issuers' terms of sale (pre-transparency), to prices and volumes of transactions carried out in the markets (post-transparency) or, in terms of risk, to aggregated information on the positions held by each dealer. For market participants, especially for those with a lower level of information, transparency makes it easier to take trading decisions and reduces search costs. For the supervisory authorities, the availability of information on aggregated positions in derivative contracts of market participants enables them to improve their prudential supervision. In retrospect, it would seem clear that the lack of information on the exposures held by AIG and Lehman Brothers in the CDS market caused problems not only for their counterparties but also made it difficult for the supervisory authorities to monitor the risks really assumed by these entities, and, especially in the case of the investment bank, limited the ability of the economic authorities to evaluate the systemic effects of its collapse.

In this context, a number of recent academic analyses have stressed the benefits that the establishment of transparency regimes in these markets might be expected to bring. These benefits can be broken down into those whose main beneficiaries would be the solvency supervisors of entities and those which would benefit market participants in terms of improvements to liquidity and transaction costs. While the advantages of having more information on transactions in terms of the effectiveness of prudential supervision would seem to be unquestionable, the effect on market participants are sometimes considered to be ambiguous, since most of the participants in these markets are major financial companies for whom the access and analysis of information is not a problem.

Thus, Avellaneda and Cont (2010) analyse the effects which an increase in transparency would have on the CDS market and conclude that the main beneficiaries would be the less well-informed participants together with those who carry out small volume transactions (in this latter case, due to the reduction of transaction costs). However, according to these authors, the structure of the CDS market would only allow these benefits to be partly exploited, since they are mainly wholesale markets. Conversely, the cost of major transactions could be increased due to increased transparency requirements and, possibly, due to a drop in the activity of market makers, who, according to this argument, would see a drop in their profits. A possible solution to this latter state of affairs would be to establish delays in the publication of transactions which exceeded a certain threshold, similar to the current regime provided for by the MiFID directive for shares.

Meanwhile, Acharya and Engle (2009) stress that transparency may help improve evaluations of counterparty risk and lead to greater efficiency in the determination and use of the margins required in contracts, since by improving information about

29 At the time this article was published, the European proposals for regulatory amendments do not include a similar provision limiting proprietary trading. 
the positions and risks of each participant, the bilateral margins could be calculated in such a way as to be better aligned with each particular risk. ${ }^{30}$ Kiff et al. (2009) highlight the fact that the fears of systemic risk in CDS markets could abate if supervisors and participants had access to more detailed information about the reference entities of the contracts and the counterparties.

With regard to the application of the post-transparency regime, it seems clear that the transfer of CDS trading to regulated markets or MTFs when the contracts meet some prior liquidity and standardisation requirements would help improve access to information for all interested parties. At the same time, when the contracts are not suitable for trading on regulated markets or MTFs, the alternative could be based on reporting trades to a central trade repository, similar to the DTCC in the USA. Supervisors would have access to information concerning entities' positions and risks. ${ }^{31}$

In this respect, some months ago the European Commission put forward a number of proposals (see European Commission, 2009) to promote the trading of standardised contracts on regulated markets and increasing the transparency of OTC markets through the establishment of central trade repositories. These proposals have finally crystallised in the aforementioned document published by the EC in September 2010, which includes a specific title where the conditions and requirements to be met by central trade repositories are set out. Thus, according to the EC proposal, these repositories should be a legal entity resident in the EU and registered with the ESMA. ${ }^{22}$ By June 2012 the ESMA will also submit to the EC the technical standards to be met by requests for authorisation from a repository. In particular, the ESMA will recognise any extra-Community entities which meet the following requirements: the repository has been authorised and is subject to the supervision of a third country with which the EC has signed an international cooperation agreement assuring the EU authorities immediate access to all necessary information.

As in the case of CCPs, the EC proposal calls for a series of requirements applicable to repositories, including the obligation to have a clear definition of the organisational structure and the lines of responsibility within each repository. The members of the Board should be people with appropriate and adequate experience. The conditions required of the participants by the repository must be objective and non-discriminatory and the fees must be public. An essential aspect to achieve the objective of increasing transparency is to ensure that information is publicly available. To achieve this objective, the rules will oblige the repositories to publish aggregated information on positions for each class of derivative. Finally, the EC requires the ESMA, the supervisors and the national central banks to have access to all the information they need to perform their duties.

30 The Committee on the Global Financial System (see CGFS, 2010) has recently proposed encouraging updating margins with greater frequency (it even suggests updating them on a daily basis) in order to avoid requests for high-volume extraordinary margins, as happened in the case of AIG described above. The CGFS also proposes that margins be calculated using long series of prices during an entire economic cycle to dampen variations in margin requirements at times of greatest tension.

31 As a result of the increase in the demand for information prompted by the European sovereign debt crisis, in March 2010 the DTCC announced its willingness to provide consolidated data regarding the positions of participants and reference entities to any regulators requesting it.

32 In order to meet this requirement, the US DTCC set up a branch in the United Kingdom with a trade registration and publication format similar to the one in the market of the parent company. 
With regard to the optimum number of repositories, the debate is similar to the one currently underway concerning CCPs. From the point of view of access to consolidated information by entity, a single repository would seem to be the most efficient solution. Some analysts and members of the industry consider that the optimal solution would consist of a single repository for each class of derivative, so as to be able to exploit economies of scale efficiently and reduce operating costs for the obligated entities that reporting transactions to several repositories means. However, at the same time the potential problems arising from some differences of a regulatory or practical nature between the different jurisdictions involved, and the problems inherent to possible monopolistic situations need to be evaluated. In particular, we need to take into account the fact that a structure with several repositories operating in different countries would require the establishment of cooperation agreements between supervisors for the exchange of prudential information.

\section{Increase in the level of standardisation}

The proposals described above, aimed at increasing transparency and promoting the move to CCP settlement of a large percentage of the trading of CDS and other OTC derivatives, could have significant effects, even in the short term, thanks to the recent progress made in the standardisation of contracts, which will be described in the following section.

- Eligible trades confirmed electronically

- Ineligible trades nor confirmed electrnically

- Trades not confirmable electronically

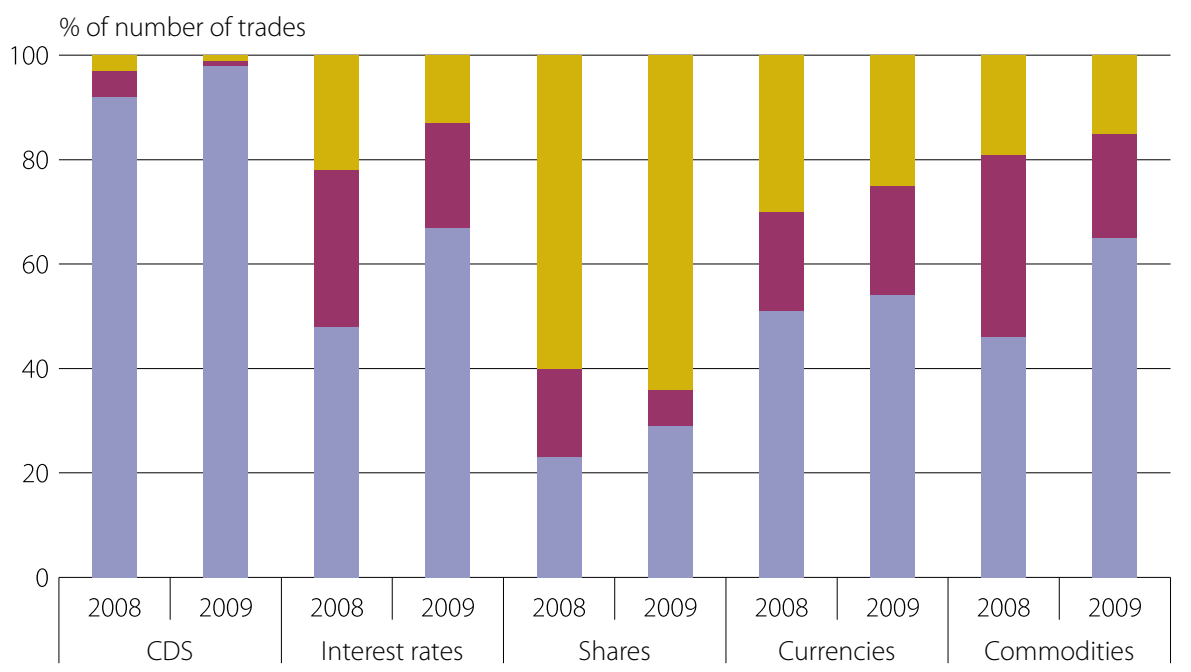

Source: ISDA.

1 Transactions corresponding to new trades, new confirmations as a result of changes in the terms of the contract, partial or total cancellations of contracts and novations. Credit events are not considered in this definition, nor are intra-corporate transactions or transactions arising from the compression of redundant contracts.

2 Trades eligible for electronic confirmation are those trades which have some advantage or facility enabling their processing on an electronic trading platform (such as Markit Wire, GFI, DTCC or Swift), regardless of the counterparties' capability of handling such a process. 
In the early years of its development, CDS were typically traded over the phone and their settlement suffered from major operational risks and delays since they were settled manually. As from 2005, a minimum degree of standardisation began to be achieved in the USA thanks to the joint work of the regulators (mainly the Federal Reserve in the USA) and the industry itself. In 2005, a significant part of CDS were still awaiting confirmation, registration, and settlement several days after trading, which meant a major source of operational risk. Since then, considerable progress has been made in electronic trading and the electronic confirmation of trades, as shown by the fact that over $95 \%$ of credit derivative trades are now confirmed electronically, with the consequent reduction in operational risk (see Figure 8). As a result of these recent advances, confirmation periods were cut from more than twenty days in 2002 to a little over four days in 200833 and, in 2009, according to ISDA figures, practically all electronic confirmations of CDS trades occurred in the two days subsequent to their trading day. The small percentage of trades which are still not confirmed electronically are more complex transactions with a lower level of standardisation, which slows down their confirmation and makes their incorporation into a automated settlement systems a complicated task. In fact, the average time until receipt of CDS trade confirmations not made by electronic means has increased to over six days in recent years. New or non-standardised products are the main cause of these delays in sending confirmations (see Table 2).

\section{Confirmations sent in CDS trades by number of business days subsequent to trading day ${ }^{1}$}
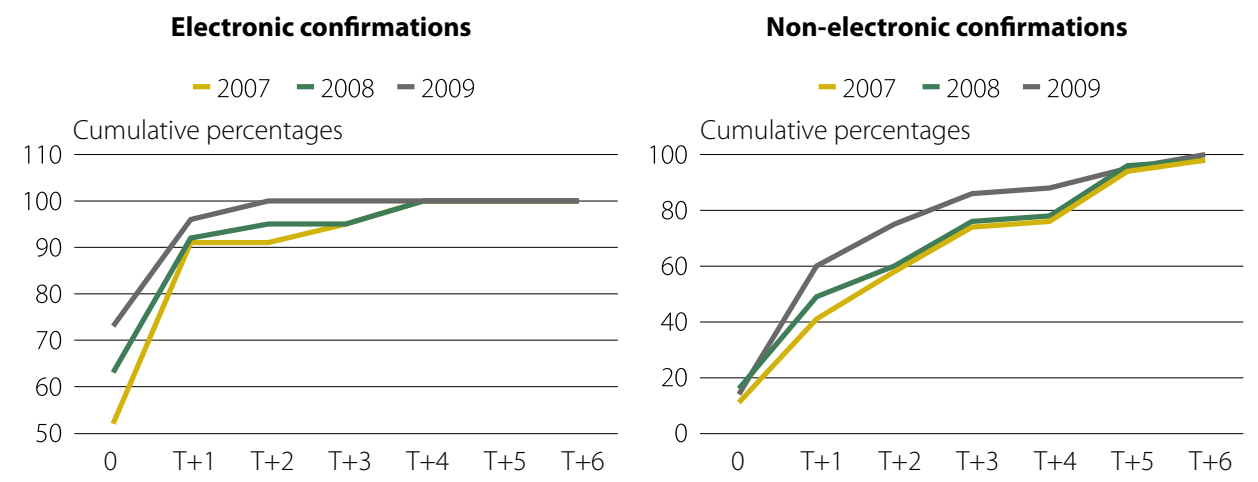

Source: ISDA.

1 The value " 0 " refers to the trading day, " $T+1$ " to the business day subsequent to that day, and so on.

Another way in which standardisation of contracts can help mitigate both operational and counterparty risk is by increasing the frequency with which parties confirm their respective contractual obligations in OTC transactions (portfolio reconciliation). Thus, a greater degree of contract standardisation would lead to fewer discrepancies between the parties with regard to the terms or the value of the contracts, which makes the reconciliation of positions less costly and, therefore, allows reconciliation to be performed on a daily basis, thereby helping to mitigate these risks. In this respect, in 2009 a little over half the major dealers reconciled their positions on a daily basis, although the other participants showed a lesser degree of rigour (see Figure 10). More

33 See Kiff et al. (2009). 
specifically, $44 \%$ of all participants (37\% of the major dealers) stated that reconciliations were carried out either less frequently (every quarter, six months, or year) or in response to a particular discrepancy. From a regulatory point of view, and regardless of the size of the participant, it would seem logical to require this practice to be carried out on a regular basis and across the board, without waiting for discrepancies to appear in the contracts before making a reconciliation.

\section{Ranking of factors which delay the sending of confirmations of CDS TABLE 2 transactions}

\begin{tabular}{llrr} 
& 2007 & 2008 & 2009 \\
\hline New or non-standard product & 1 & 1 & 1 \\
\hline Large volumes & 2 & 2 & 3 \\
\hline Non-standard language & 3 & 4 & 4 \\
\hline Delays in information or approval from legal affairs & 4 & 4 & 5 \\
\hline Delays in information or approval from traders & 5 & 3 & 2 \\
\hline Technological or IT system problems & 6 & 6 & 8 \\
\hline Delays in the information provided by external sources & 7 & 7 & 6 \\
\hline Delays in the information or approval from credit risk control departments & 8 & 8 & 7 \\
\hline
\end{tabular}

\section{Frequency of reconciliation of positions in OTC derivative portfolios ${ }^{1,2} \quad$ FIGURE 10}

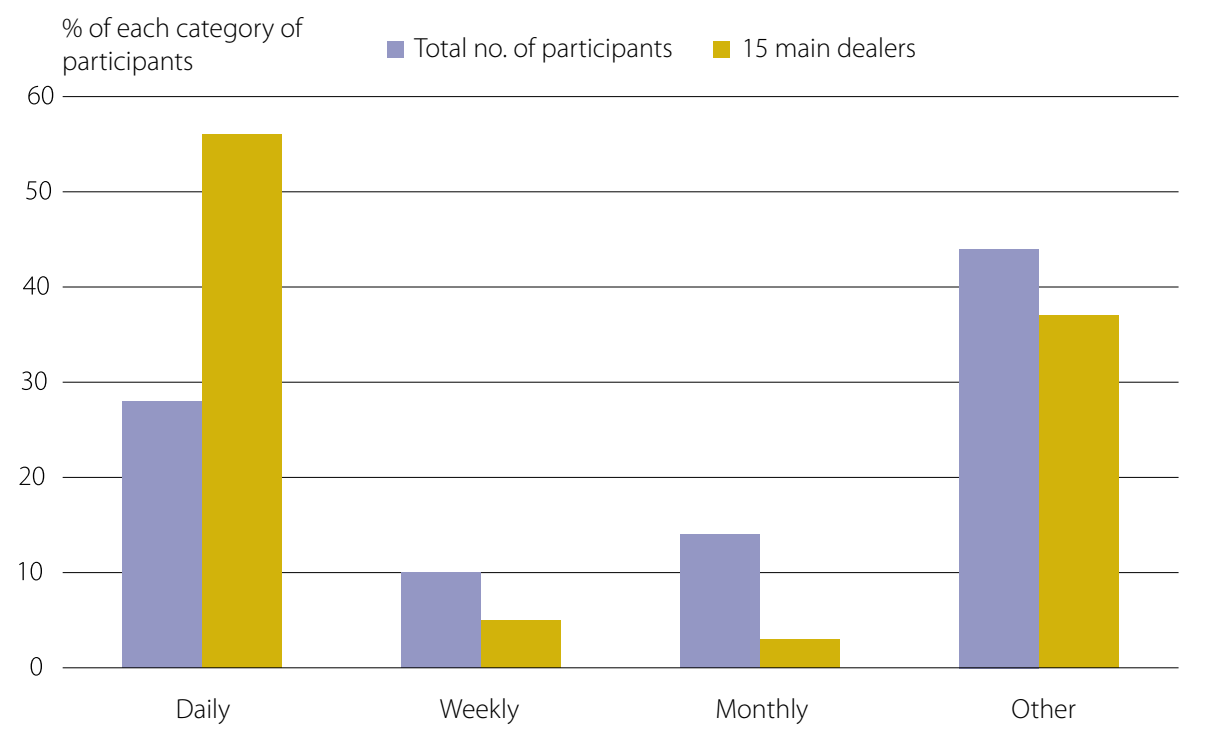

Source: ISDA.

1 The category "Other" refers to a lesser frequency (quarterly, half-yearly, or yearly) and to ad hoc reconciliations or those prompted by a particular dispute over the terms or the value of the contracts.

2 The percentages do not add up to 100 due to incomplete answers in the ISDA survey.

The introduction in 2009 by the ISDA34 of two protocols containing substantial changes to the conventions of the less complex CDS contracts, has meant one of the

34 See Markit (2009a and 2009b). The Quarterly Bulletin of the CNMV for the third quarter of 2009 (chapter 1) contains a description of the main aspects of the two ISDA protocols. These protocols exclude some 
greatest efforts made by the industry to date to increase the fungibility and liquidity of these contracts. The first of these protocols, known as Big Bang, incorporates a number of changes of across-the-board application which are focused on improving the efficiency of the settlement of contracts in the event of the bankruptcy of its reference entity, via the harmonisation of settlement criteria. This protocol also contains provisions applicable exclusively to the USA to promote the standardisation of the payment of coupons so that there are only a limited number of possible alternatives, which will ultimately increase their liquidity.

The second ISDA protocol, known as Small Bang, is an extension of the previous one and includes changes to the convention of European CDS, very similar to those introduced by Big Bang for US CDS, and changes to the definition of a credit event applicable to European contracts, so that the debt restructuring of the reference entity will continue to be a credit event.

\begin{tabular}{|c|c|c|}
\hline & USA & Europe \\
\hline Targeted entities & $\begin{array}{l}\text { Financial counterparties and } \\
\text { participants which represent a } \\
\text { systemic risk (major swap } \\
\text { participants). }\end{array}$ & $\begin{array}{l}\text { Financial and non-financial } \\
\text { counterparties with different } \\
\text { hedging positions and which } \\
\text { exceed the threshold to be set } \\
\text { by the ESMA. }\end{array}$ \\
\hline $\begin{array}{l}\text { Obligation of trading on } \\
\text { exchanges }\end{array}$ & $\begin{array}{l}\text { For standardised CDS. May also } \\
\text { be traded on specific swap } \\
\text { platforms. }\end{array}$ & No. \\
\hline Limitation on proprietary trading & Yes. & No. \\
\hline Obligation of settlement in a CCP & $\begin{array}{l}\text { For standardised CDS. Non- } \\
\text { financial counterparties are } \\
\text { exempt unless they are } \\
\text { considered to be major swap } \\
\text { participants. }\end{array}$ & $\begin{array}{l}\text { For standardised CDS. Non- } \\
\text { financial counterparties with } \\
\text { positions under the threshold } \\
\text { will be exempt. }\end{array}$ \\
\hline Requirements for CCPs & $\begin{array}{l}\text { - Sufficient resources to cope } \\
\text { with the default of the largest } \\
\text { participant. } \\
\text { - Limitation al } 20 \% \text { of the capital } \\
\text { in CCP for banks and dealers }\end{array}$ & $\begin{array}{l}\text { - Five million euros. } \\
\text { - Sufficient resources to cope } \\
\text { with the default of the largest } \\
\text { participant. } \\
\text { - Creation of a settler's fund. }\end{array}$ \\
\hline $\begin{array}{l}\text { Settlement of non-standardised } \\
\text { CDS }\end{array}$ & $\begin{array}{l}\text { - Capital requirements and } \\
\text { initial guarantees. }\end{array}$ & - Capital requirements. \\
\hline Transparency & $\begin{array}{l}\text { - Communication of CDS } \\
\text { contracts to central } \\
\text { repositories. }\end{array}$ & $\begin{array}{l}\text { - Communication of CDS } \\
\text { contracts to central } \\
\text { repositories. }\end{array}$ \\
\hline
\end{tabular}

Source: CNMV.

In the field of regulatory initiatives, the European Commission (2009) is evaluating a possible change to the treatment given to operational risk in the Capital Requirements Directive in order to promote a greater level of contract standardisation in OTC markets and a greater use of electronic confirmation. This measure aims to

of the more complex derivatives, such as those that have securitised assets as their underlying. 
reduce operational risks, by ensuring that transaction confirmation and registration happen in real time.

In short, the objectives pursued by regulators and the industry with regard to standardisation are focused on increasing the level of homogeneity of the main market conventions so as to facilitate the settlement of CDS contracts in CCPs and to reduce the volume of redundant contracts.

Finally, while in Spain financial institutions have not marketed products structured with credit derivatives on a massive scale, it may be advisable to include a regulatory provision which places certain limits on the marketing of these products to retail investors. Such a provision would be based on the binary nature of CDS risk profiles and the difficulty to estimate potential losses, which is especially complex when there are several reference assets.

\subsection{Restrictions on naked CDS}

Coinciding with the most acute period of turbulence seen in some European debt markets during the first half of 2010, various analysts and European political authorities proposed placing restrictions on naked sovereign CDS when the CDS buyer does not hold the reference bonds of the contracts 35 and therefore opens an outright short position on the sovereign credit risk. In this section we make a critical review of the argument for placing strong restrictions on or banning this practice. In particular, we go on to argue that banning naked sovereign CDS trades across the board raises two significant types of problem, the first related to the harm that a measure of this type would cause in terms of loss of efficiency in the functioning of both the CDS and the reference sovereign bond markets, and the second relating to the difficulties in implementing it effectively. ${ }^{36}$

Firstly, with regard to the damaging effects of a ban, it should be pointed out that denying investors who do not hold sovereign bonds access to CDS markets effectively removes a source of information, the immediate effect of which is a reduction in the information content of the prices of these products, which will normally make it more difficult to estimate their true risk. In this regard, it is important to bear in mind that an increase in the number of counterparties in any market increases the market's liquidity and, under normal conditions, also increases its efficiency.

On the other hand, it is also important to bear in mind that some investors buy sovereign CDS without holding any simultaneous position in the corresponding bond

35 Portes (2010) sets out several arguments in favour of the prohibition of the naked buying of CDS. In open opposition to this thesis, the American Enterprise Institute for Public Policy Research (2009) considers intervention in the CDS market regarding naked positions to be unnecessary, while being critical of the idea of creating central clearing houses in which to settle these products.

36 Portes (2010) sets out several arguments in favour of the prohibition of the naked buying of CDS. In open opposition to this thesis, the American Enterprise Institute for Public Policy Research (2009) considers intervention in the CDS market regarding naked positions to be unnecessary, while being critical of the idea of creating central clearing houses in which to settle these products. 
as a way to protect themselves against the default of other credit products for which there is no CDS (or whose market has a low level of liquidity), but whose risk positively correlates with a default of the sovereign bond in question (for example, public companies debt, debt issued by local and regional bodies, etc). In this respect, it is clear that removing this last possibility of hedging such a risk is undesirable. In fact, one of the exemptions provided for in the recent ban applied by the German financial supervisory authority (BaFin) on naked sovereign CDS in the Eurozone refers to naked purchases aimed at insuring positions which, while not the same as holding the reference sovereign bond, do lose value when the solvency of the sovereign state in question worsens.

Secondly, it is important to point out that there are several practical difficulties for implementing this type of ban effectively. Indeed, the exemption to the ban on naked sovereign CDS provided for by the BaFin illustrates the immense complexity of implementing this type of restriction, especially in the current circumstances of exceptional macroeconomic uncertainty in which the relationship between sovereign risk and risk attributable to other issuers is intensifying. This makes it more difficult for the supervisor to discriminate between naked purchases aimed at indirectly hedging non-sovereign risk and purely speculative trades with no intention whatsoever to protect against risk.

It is clear, then, that it is practically impossible to establish objective criteria that can determine which exposures to non-sovereign risk actually have a positive relationship with sovereign risk, and supervise fulfilment of those criteria. On the one hand, making the scope of the definition of exempt naked purchases too limited would prevent many investors who are looking for genuine protection for their non-sovereign debt assets from having access, which could increase the general sensation of risk and trigger divestments in these positions. On the other hand, a scope which is too wide would logically mean that the restrictions would have no practical effect.

Furthermore, it is important to bear in mind that, aside from naked CDS purchases, investors have other alternative channels through which to hedge their expectations of an increase in the risk of sovereign bonds, such as by trading in other derivatives (for example, options), direct or short selling of sovereign bonds, etc. Also, a ban of this nature could only produce tangible results if it is carried out worldwide. If this were not the case, the global nature of the major players in these markets would probably lead to naked buying moving from jurisdictions where there are restrictions to others where trading is unrestricted. This would probably mean that the effect on aggregate prices and volumes traded would be limited.

Finally, in light of the arguments above, it would seem sensible to conclude that the best way of preventing abusive or manipulative conduct in the European sovereign CDS markets would be the rigorous application of the Market Abuse Directive (MAD). At the same time, it might be a good moment to make changes to that directive if any were deemed necessary, taking advantage of the fact that the directive is currently being reviewed by the European Commission. Specifically, it would be advisable for the MAD reform process to broaden the scope of the instruments to which it applies (including OTC derivatives and, especially, CDS) and to fine-tune the definition of manipulation so as to include manipulation carried out on one instrument through another derivative. At the same time, Europe should take advan- 
tage of the current review process of the MiFID Directive (on markets and financial dealers) so as to expressly require the open publication of data on the prices and volumes of each transaction and daily reporting to supervisors by including OTC derivatives in the transaction reporting system provided for in the MiFID Directive.

Fortunately, the situation in Spain does not require significant legislative changes relating to market abuse or transaction reporting as it is already mandatory to inform the CNMV about traded CDS whose underlying asset is a security traded on European markets. Also, Spanish legislation on market abuse is applicable to these products

Meanwhile, the proposed regulation announced by the EC in September 2010 provides for the reporting of naked positions in sovereign CDS in line with those established for net selling positions in shares and sovereign debt. The EC will delegate the establishment of thresholds beyond which it will be necessary to report naked selling positions in CDS and changes to those positions to the supervisory authorities. Also, the recent EC proposal includes the possibility of limiting naked CDS trades in situations which might constitute a serious threat to financial stability or to confidence in one or several EU Member States. However, when a CDS is used as a hedge, it will be exempt from the prohibition. Thus, although the specific definition is still to be reached, in principle the purpose of hedging will be accepted when the buyer of a sovereign CDS holds a sovereign bond or debt from an issuer whose bonds are closely correlated with the reference sovereign bond. However, the notion of strong correlation has not yet to be quantified which, as mentioned earlier, evidences the practical difficulty of defining what a naked position is in this context.

Finally, one regulatory possibility which is yet to be explored in the CDS segment is the setting of limits on open positions for each entity according to the outstanding balance of the reference assets. The purpose of this measure, initially used in regulated commodity derivative markets, is to limit distortions in spot prices caused by the naked trading of derivative instruments. However, as has been stated earlier, in the case of sovereign debt the ratio of the volume of CDS to the outstanding balance of debt will normally be very small (see Table 1). 



\section{Conclusions}

The controversy surrounding CDS has increased since the crisis began, firstly, as a result of their connection with the bankruptcy of Lehman Brothers and the collapse of AIG in 2008 and, subsequently as a consequence of the turbulence affecting several European sovereign debt markets, especially during the first half of 2010 . In the context of growing disparity in the arguments in favour and against these products, this article attempts to shed some light on those aspects of the functioning of CDS markets which, to a high degree of certainty, require urgent and ambitious improvements, as opposed to others for which available analysis and evidence suggest a more cautious approach.

Among the former, the lack of transparency, both prior to trading and after it, and the risk of default by the counterparties are highlighted as the most pressing problems. The solution to these problems requires a growing volume of these contracts to be traded and settled in central counterparty clearing houses (CCPs), subject to appropriate requirements of supervision, capitalisation and transparency. In this respect, the proposals put forward by the G-20 have recently crystallised in concrete regulatory measures in both the European Union and the USA, which should be implemented urgently and ambitiously, in a spirit of close coordination and cooperation between the various economic and supervisory authorities.

Regarding the hypothesis whereby CDS play a destabilising role in public debt markets and the corresponding proposals to restrict some sovereign CDS trades, the arguments put forward in this article suggest, first of all, that there is a lack of evidence to suggest with any certainty that these derivative products have played a decisive role in the recent episodes of high volatility in some sovereign debt markets. Secondly, the article sets out a series of arguments about the damage which could be caused, barring extreme situations, by certain restrictive measures against the naked buying of CDS. In particular, restricting this type of practice may give rise to a loss of efficiency and liquidity in CDS markets, while their practical application is no easy task either. 



\section{Bibliography}

Acharya, V. and Engle, R. (2009). A case for (even) more transparency in the OTC markets.

Alexopoulou, I., Andersson, M. and Georgescu, O.M. (2009). An empirical study on the decoupling movements between corporate bond and CDS spreads. European Central Bank, Working Paper Series No. 1085.

American Enterprise Institute for Public Policy Research (2009). Unnecessary Intervention: The Administration's Effort to Regulate Credit Default Swaps. Outlook Series, August.

Ammer, J. and Cai, F. (2007). Sovereign CDS and Bond Pricing Dynamics in Emerging Markets: Does the Cheapest-to-Deliver Option Matter? Board of Governors of the Federal Reserve System, International Finance Discussion Papers No. 912.

Arce, O., Mayordomo, S., and Peña, J.I. (2010). An analysis of the relation between the European sovereign credit default swap and bond markets. Mimeo. Comisión Nacional del Mercado de Valores (CNMV).

Arora, N., Gandhi, P., and Longstaff, F.A. (2009). Counterparty credit risk and the credit default swap market. UCLA Anderson School.

Attinasi, M.G., Checherita, C. and Nickel, C. (2009). What explains the surge in euro area sovereign spreads during the financial crisis of 2007-09? European Central Bank, Working Paper Series No. 1131, December.

Avellaneda, M. and Cont, R. (2010). Transparency in credit default swap markets. Finance Concepts, July.

Bank for International Settlements (2010). OTC derivatives market activity in the second half of 2009.

Blanco, R., Brennan, S. and Ian, W. (2005). "An empirical analysis of the dynamic relationship between investment-grade bonds and credit default swaps". Journal of Finance, 6o(5), pp 2255-81.

British Bankers Association (2006). Credit Derivatives Report 2006.

Cecchetti, S., Gyntelberg, J. and Hollanders, M. (2009). "Central counterparties for over the counter derivatives". BIS Quarterly Review, pp 45-58, September. 
Committee of European Securities Regulators (2008). Transparency of corporate bond, structured finance product and credit derivatives markets. Consultation Paper, Ref. CESR/o8-1014.

Committee on Payment and Settlement Systems (CPSS) and IOSCO (2010). Guidance on the application of the 2004 CPSS-IOSCO Recommendations for Central Counterparties to OTC derivatives CCPs. Advisory report, CPSS Publications No. 89, available at http://www.bis.org/publ/cpss89.pdf.

Committee on Payment and Settlement Systems (CPSS) and Technical Committee of IOSCO (2010). Considerations for trade repositories in OTC derivatives markets. Advisory report, available at http://www.iosco.org/library/pubdocs/pdf/IOSCOPD321.pdf.

Committee on the Global Financial System (2010). The role of margin requirements and haircuts in procyclicality. CGFS Papers, No. 36, March.

De Wit, J. (2006). Exploring of CDS-Bonds basis. National Bank of Belgium, Working Paper Research No. 104.

Duffie, D. (2010a). "Credit default swaps on government debt: Potential implications of the Greek debt crisis". Declaration in the Subcommittee on Capital Markets, Insurance, and Government Sponsored Enterprises (US House of Representatives), April.

Duffie, D. (2010b). "Is there a case for banning short speculation in sovereign bond markets?" Banque de France, Financial Stability Review No. 14, pp 55-59, July.

Duffie, D., Li, A. and Lubke, T (2010). Policy perspectives on OTC derivatives markets infrastructure. Federal Reserve Bank of New York Staff Reports N. 424

Duffie, D. and Zhu, H. (2010). "Does a central counterparty reduce counterparty risk?" Manuscrito, Stanford University.

Elizalde, A. and Doctor, S. (2009). The bond-CDS funding basis. J. P. Morgan. European Credit Derivatives Research.

Elizalde, A., Doctor, S. and Saltuk, Y. (2009). Bond-CDS basis handbook. J. P. Morgan. European Credit Derivatives Research.

European Central Bank (2009). Credit Default Swaps and Counterparty Risk. Available at http://www.ecb.int/pub/pdf/other/creditdefaultswapsandcounterpartyriskzoogen.pdf .

European Commission (2009). Ensuring Efficient, Safe and Sound Derivatives Markets: Future Policy Actions. Communication of the EC, available at http://ec.europa. eu/internal_market/financial-markets/docs/derivatives/20091020_563_in.pdf.

European Commission (2010a). Public consultation on derivatives and market infrastructures. EC public consultation document, available at http://ec.europa.eu/internal_market/consultations/docs/2010/derivatives/100614_derivatives.pdf. 
European Commission (2010b). Proposal for a regulation of the European Parliament and the Council on OTC derivatives, central counterparties and trade depositories. Available at http://ec.europa.eu/internal_market/financial-markets/docs/derivatives/20100915_proposal_in.pdf

European Commission (2010c). Proposal for a regulation of the European Parliament and the Council on naked short selling and certain aspects of credit default swaps. Available at http://ec.europa.eu/internal_market/securities/docs/short_selling/20100915_proposal_in.pdf

Financial Stability Board (2010). Implementing OTC Derivatives Market Reforms. Available at: http://www.financialstabilityboard.org/publications/r_101025.pdf.

Fitch Ratings (2009). Global Credit Derivatives Survey: Surprises, Challenges and the Future. Special Report.

Fitch Ratings (2010). Global Credit Derivatives Survey: Respondents Opine on Public Perceptions, Regulations, Sovereigns, and More. Credit Market Research.

International Monetary Fund (2010). Global Financial Stability Report, April.

Hull, J. (2010). OTC derivatives and central clearing: can all transactions be cleared? University of Toronto.

Hull, J., Predescu, M. and White, A. (2004). "The relationship between credit default swaps spreads, bond yields, and credit rating announcements". Journal of Banking and Finance, 28, pp 2789-2811.

International Swaps and Derivatives Association (2010). Market Review of OTC Derivative Bilateral Collateralization Practices. ISDA Collateral Steering Committee.

Kiff, J., Elliot, J., Kazarian, E., Scarlata, J. and Spackman, C. (2009). Credit derivatives: systemic risk and policy options. IMF Working paper WP/o9/254.

Litan, R.E. (2010). The derivatives dealers' club and derivatives markets reforms: A guide for policy makers, citizens and other interested parties. The Brookings Institution, Initiative on Business and Public Policy at Brookings.

Longstaff, F.A., Mithal, S. and Neis, E. (2005). “Corporate yield spreads: default risk or liquidity? New evidence from the credit default market". Journal of finance, vol. 6o, No. 5, pp 2213-53.

Mayordomo, S., Peña, J.I. and Romo, J. (2009). Are there arbitrage opportunities in credit derivatives markets? A new test and an application to the case of CDS and ASPs. Universidad Carlos III de Madrid, Business Economics Working Papers N. wbog6303.

Mayordomo, S., Peña, J.I. and Romo, J. (2010). The Effect of Liquidity on the Price Discovery Process in Credit Derivatives Markets in Times of Financial Distress. CNMV, Working Paper No. 41. Accepted for publication in the European Journal of Finance. 
Mayordomo, S., Peña, J.I., and Schwartz, E. S. (2010). "Are all Credit Default Swap Databases Equal?” Mimeo. Comisión Nacional del Mercado de Valores (CNMV).

Norden, L. and Weber, M. (2004). "Informational Efficiency of Credit Default Swap and Stock Markets: The Impact of Credit Ratings Announcements". Journal of Banking and Finance, 28, pp 2813-2843.

Portes, R. (2010). "Ban Naked CDS". Unpublished manuscript, London Business School.

Squam Lake Working Group on Financial Regulation (2009). Credit Default Swaps, Clearinghouses, and Exchanges. Council on Foreign Relations, Center for Geoeconomic Studies, Working Paper.

Stulz, R.M. (2010). "Credit Default Swaps and the Credit Crisis". Journal of Economic Perspectives, vol. 24, No. 1, pp 73-92.

Trapp, M. (2009). Trading the Bond-CDS Basis. The Role of Credit Risk and Liquidity. Centre of Financial Research, Working Paper No. o9-16.

Zhu, H. (2006). "An empirical comparison of credit spreads between the bond market and the credit default swap market". Journal of Financial Services Research, 29(3), pp $211-235$. 



